Article

\title{
An Environmental Perspective on Clothing Consumption: Consumer Segments and Their Behavioral Patterns
}

\author{
Wencke Gwozdz *, Kristian Steensen Nielsen and Tina Müller \\ Department of Management, Copenhagen Business School, Society \& Communication, CBS Centre for \\ Corporate Social Responsibility (cbsCSR), Porcelænshaven 18A, DK-2000 Frederiksberg, Denmark; \\ ksn.msc@cbs.dk (K.S.N.); tm.msc@cbs.dk (T.M.) \\ * Correspondence: wg.msc@cbs.dk; Tel.: +45-3815-3391 \\ Academic Editor: Gerrit Antonides
}

Received: 15 February 2017; Accepted: 2 May 2017; Published: 6 May 2017

\begin{abstract}
Efforts to decrease the environmental impact of today's clothing industry across the entire process of production, purchase, maintenance, and disposal can be driven by either suppliers or consumers. Changing the behavior of the latter, however, requires an understanding of current clothing consumption patterns-a currently under-researched area. We therefore shed more light on these patterns in the purchase, use and maintenance, and discard phases by analyzing unique data on 4617 adult consumers (aged 18-65) from Germany, Poland, Sweden, and the U.S., who we divide into five segments based on clothing consumption behavior. At the low end of the spectrum is a consumer segment that earns the least, consumes mostly budget brand clothing, and is the least open to alternative more environmentally friendly business models such as fashion leasing or clothing libraries. At the other extreme lies a small segment that earns the most, engages in high consumption of medium or premium brand clothing, and is most open to alternative business models. Lying between these two is a primarily female segment that purchases an above average amount of clothing from budget brands. In addition to the segments' different reported purchase behavior and a varying openness to alternative business models, we identify differences in willingness to pay for clothing made of material that is more environmentally friendly than conventional fabrics. These observations suggest several promising directions for environmental interventions tailored toward specific consumer segments.
\end{abstract}

Keywords: clothing consumption; consumer segmentation; environmental impact; Western countries

\section{Introduction}

In addition to meeting the basic human need for protection against weather variations, clothing functions as a means of personal communication by which individuals express themselves through their clothing choices. Because this practice has persisted over recorded human history, it might be regarded as an acquired human need [1]. Nonetheless, the clothing industry of today has moved well beyond merely satisfying basic physiological and psychological needs, and the rise of fast fashion, especially, has greatly altered clothing's societal and cultural significance. In particular, fast fashion has drastically shortened the clothing life cycle, with new styles swiftly superseding the old. Not only do many fast fashion retailers (e.g., H\&M or Forever 21) introduce new merchandise on an almost weekly basis and deliberately manipulate the supply to create "must have" items targeted primarily at young consumers [2,3], but fast fashion products also tend to have a short lifespan [4]. This brevity is not necessarily a result of the clothing's intrinsic quality but rather may stem from a reduction in the products' symbolic value (e.g., being outdated by newer trends). Overall, therefore, the fast 
fashion industry is characterized by short-term use, symbolic obsolescence, and increasing waste generation [5], meaning that its rise has had detrimental consequences for the environment. In fact, the clothing industry is currently one of the world's most polluting industries [6], heavily impacting the environment through its immense use of water and chemicals during production (e.g., for growing cotton or dying textiles), as well as ecosystem pollution, and textile waste generation [6,7]. However, even though much environmental degradation can be attributed to the clothing industry, an equal part of the responsibility is borne by consumers, who, rather than being mindless market actors with no control over clothing's environmental impact, are instrumental in determining the number, frequency, and type of clothing items purchased, how these items are used and maintained, and the means of disposal once items are worn out or no longer wanted. All these consumer-related aspects have implications for clothing's final impact on the environment (see, e.g., [1]).

The purpose of the present study, therefore, is to assess consumer behavior as it relates to each of these aspects-with particular attention to current clothing consumption patterns through the purchase, use and maintenance, and disposal phases-as well as this behavior's implications for environmental sustainability. We do so using a consumer segmentation analysis that not only addresses consumer heterogeneity but, instead of characterizing the segments demographically as is common in previous research, differentiates them by purchase behavior. Such segmentation contributes to a better understanding of clothing consumption, one that can inform the development of targeted behavior change interventions. Our analysis also contrasts with previous empirical work in environmentally friendly and unfriendly clothing consumption in that rather than using small-scale or one-country samples to focus on one of the three consumption phases, it employs large diverse samples from four countries (Germany, Poland, Sweden, and the U.S.) to trace behavior patterns across all three phrases. It thus makes a unique contribution to this literature stream in both scope and analytical approach. Before reporting our results, however, we present an overview of the primary environmental concerns related to the clothing life cycle and then describe our sample and methodology.

\section{Background}

Because the evolution of fast fashion and the subsequent globalized mass consumption of clothing have greatly influenced the state of the environment, we begin our discussion with an explanation of how production and purchase, use and maintenance, and the eventual disposal of clothing each creates different environmental concerns. Although a lack of supply chain transparency and traceability from clothing retailers makes it impossible to attribute some of these concerns directly to consumers, other problems could be directly alleviated or accommodated by changes in consumer purchase and post-purchase behavior patterns.

\subsection{Production and Purchase}

The high resource intensity of clothing production makes it the primary source of environmental degradation in the clothing life cycle [1], with particularly heavy environmental impacts from voluminous use of energy, water, and chemicals. The production of one pair of jeans, for instance, requires 3625 liters of water, 3 kilograms of chemicals, $400 \mathrm{MJ}$ of energy, and $16 \mathrm{~m}^{2}$ of harvested land [8]. The clothing industry is thus high on energy consumption but low on energy use efficiency [9], with most energy in clothing production consumed during weaving, spinning, and chemical processing [6]. During 2008, for example, textile and clothing production used 1074 billion $\mathrm{kWh}$ of electricity (or 132 million tons of coal) [10].

Clothing production also consumes vast amounts of water, a resource that is becoming increasingly scarce across the globe because of climate change, pollution, and overuse. The primary source of water usage is in the production of cotton, a water-intensive crop that may need as much as 8.5 tons per kilogram [11]. The fabric preparation process of desizing, scouring, and bleaching also depends on water throughout, and nearly all textile dying and application of specialty or finishing chemicals occurs in water baths. Even worse, following each process, the fabrics are washed to remove used chemicals 
and the water is returned to the ecosystem, often without any purification efforts, which leads to water pollution [12]. Hence, in addition to an estimated nine trillion liters of water per year [12], textile processing also uses about $25 \%$ of the chemicals employed in production globally [13]. Even synthetic fibers, such as polyester, although developed in factories independent of water, have a negative impact because of their derivation from fossil hydrocarbons [14].

Naturally, the environmental concerns arising from the production phase are highly interconnected with those from the purchase phase, although in this latter phase, consumers, through their purchasing power, have the volitional capacity to choose items made of more environmentally friendly and higher quality materials (e.g., lyocell fibers such as Tencel ${ }^{\circledR}$ ) than are conventional. Consumers also decide when new clothing items are needed and how many should be purchased. Hence, the purchase phase is critically important to clothing's environmental impact through its strong interaction with the other life cycle phases. For example, whereas garment quality inherently influences maintenance and eventual necessity for disposal, the sheer volume of clothing items sold has profound implications for the environmental impact of the production phase. Over recent decades, this volume has been rising, with private consumption of clothing and shoes in Sweden increasing by $53 \%$ from 1999 to 2009 [15], including an average purchase of nine $t$-shirts per year [16]. In America, as of 2013, the average consumer purchased 64 clothing items per year with an associated expenditure of $\$ 907$ [17], approximately $\$ 14.17$ per item. However, most consumers still do not link their clothing consumption patterns with environmental degradation [18,19].

In fact, this increasing consumption comes at a high environmental cost, one that Roos et al. [20] suggested can be most efficiently reduced by increasing the service life of clothing items whenever feasible to lower overall consumption rates. Another possible solution is to use more environmentally friendly materials, which, although increasingly more available in clothing stores, still represent only a niche on the global market. Even when such materials are relatively plentiful—for example, organic cotton with a market value of $\$ 15.7$ billion for an annual production of 112,488 tons of fiber [21] - it is unclear to what extent consumers are willing to pay an additional cost for clothing made from these materials. The empirical evidence on this issue is inconclusive: whereas over half of Ha-Brookshire and Norum's respondents were willing to pay a premium for t-shirts made from U.S.-grown organic cotton [22], participants in a study by Ellis et al. reported that when purchasing clothes for themselves, they were unwilling to pay a premium for an organic cotton t-shirt [23].

Another important aspect is clothing acquisition, alternative forms of which have slowly become more popular (particularly in urban areas) in the form of clothing libraries, swap markets, fashion rentals, and second-hand stores. Although these alternative business models may represent a more environmentally friendly approach to clothing acquisition, their ability to lower clothing's environmental impact may be highly dependent on the consumer's transportation mode to and from the store [15]. That is, if using alternative models involves increased consumer transportation (e.g., more driving), the environmental benefits are likely to evaporate.

\subsection{Use and Maintenance}

Clothing can be costly to maintain both from a monetary and environmental perspective; especially as most maintenance practices are strongly influenced by social norms of high level hygiene and cleanliness. Adherence to these social norms, however, often involves an environmental burden of energy, water, and detergent use [24]. Europeans, for example, wash their clothes at an average temperature of $45.8^{\circ} \mathrm{C}$ [25], a practice whose environmental impact is dependent on geographic and demographic context, including specific energy source [1]. When the energy source is renewable, wash temperature has a lower environmental impact, but when the energy comes from fossil fuels, the impact rises significantly. In addition to the associated environmental impact, how often clothing is washed may also have implications for product life because laundering contributes to wear and tear [26]. Among young Swedish consumers, for example, the average number of wearings before washing is two to three times for t-shirts, shirts, and tops but four or more times for trousers and skirts [27]. Although 
$38 \%$ of these young consumers use eco-labeled detergents, reflecting the increasing replacement of harmful chemicals with bio-based, degradable ingredients [28], consumers typically experience difficulties fully understanding dosing instructions, which may lead to overuse [29].

The environmental burden increases if laundering includes tumble drying, which consumes 3-4 times more energy than washing at $40^{\circ} \mathrm{C}$ [1] but is used after around $20 \%$ of washing cycles [30]. Admittedly, such statistics should be interpreted with caution because dryer ownership varies greatly from $16 \%$ of all households in Poland to $83.4 \%$ in the U.S. [31,32]. Nevertheless, lowering washing temperatures and eliminating tumble drying and ironing would reduce a clothing product's energy consumption by $50 \%$ [33].

\subsection{Discarding}

The excessive consumption of clothing items generates an overflow of discarded clothing, a throw-away culture that is particularly evident in developed economies. According to the U.S. Environmental Protection Agency (EPA), in 2014, the U.S. generated 16 million tons of textile and clothing waste, $64.5 \%$ of which was sent to landfills with only $16.2 \%$ recycled [34]. In the U.K., although the average lifetime of a clothing item is 2.2 years, approximately $30 \%$ of these owned clothes have probably not been worn for a year, leading to an estimated $£ 140$ million worth of used clothing (350,000 tons) being sent to landfills each year [35].

Although clothing disposal takes many forms, including binning, reselling, recycling, donating to charity, and using unwanted clothes as rags, the European Commission's 2008 Waste Framework Directive provides clear guidance on the most environmentally significant methods [36]. This directive outlines a waste hierarchy based on environmental impact, with prevention (e.g., using fewer materials or keeping products longer) being the lowest, followed by (preparation for) reuse and recycling. The highest impact methods are recovery (e.g., incineration with energy recovery) and binning (e.g., landfilling or incineration without energy recovery). Although the directive applies to all waste handling, it is especially valid in a clothing context [37,38], in which the greatest energy and carbon emissions savings are achieved by increasing clothing longevity and direct reuse, and the next greatest by reuse through charity donation and material recycling [37-39]. However, even though many consumers discard their clothing by passing it on to family members, donating it to charity, or using it as rags [26,40], binning unwanted clothing (i.e., sending it to landfills or incineration) is still common, leading to much clothing ending up in landfills or incinerators that could have been reused, recycled, or otherwise down-cycled. This widespread disposal carries a heavy environmental burden [34,35], especially given that the synthetic materials widely used in fast fashion do not decompose, while clothes made from natural fibers such as wool, although decomposable, produce the highly potent greenhouse gas, methane.

\section{Data and Methods}

To gain new insights into consumer clothing consumption behavior, we administered an online survey in Germany, Poland, Sweden, and the U.S., countries selected to provide a broad but representative spectrum of clothing markets within the Western world. Whereas Sweden has a modern and increasingly sustainability oriented fashion market, Germany is the largest economy in Europe with a major clothing market similar to that of the U.S., which is also included because of its cultural and political distinction from continental Europe. Poland, on the other hand, is representative of Eastern Europe and thus a post-communist regime, but one that largely accepts materialistic values. Because the survey questionnaire addressed not only demographics and consumer behavior throughout the three consumption phases but also concepts beyond the focus of this current study, it was split into two parts to avoid participant fatigue. 


\subsection{Data Collection}

The survey was administered between October 2016 and January 2017 by the private research software company, Qualtrics, which was responsible for contacting potential participants and collecting data in collaboration with its local panel partners. The questionnaire was first developed in English and then translated into German, Polish, and Swedish by ISO17100 certified translators. These translations were proofread by native speakers and all ambiguities resolved in collaboration with the translators before the survey was implemented online. The survey employed numerous quality measures to maximize data quality and screen out careless responses, including instruction-based attention filters ("Please select strongly agree"), bogus items ("I always sleep less than one hour per night"), response pattern indicators (e.g., straight-lining), time filters, and self-reported data quality checks (e.g., "I gave this study enough attention") [41,42]. Participants failing the instruction-based attention filters were eliminated automatically while those failing multiple quality checks were replaced. All participants received an incentive for taking part in the study in the form of points redeemable for rewards such as airline miles or gift cards.

\subsection{The Sample}

The sample for Part I of the survey, taken from the target consumer population aged 18 to 65 , is representative on age, gender, region, and education. Although participants themselves made the decision of whether to return for Part II, subjecting the process to a self-selection bias, we also strove for representativeness in this second sample. The final sample consists of respondents who participated in both survey parts for a total of around 1000 participants for each country $(N=4617)$, with 1174 from Germany, 1116 from Poland, 1182 from Sweden, and 1145 from the U.S. The mean participant age is 42.21 years $(S D=13.59)$, and females are slightly overrepresented at $56.70 \%$.

\subsection{Measurements}

To the best of our knowledge, most of our survey items on clothing consumption behavior are totally new, meaning no pre-existing standard item formulations or tested scales. Hence, all items and answer categories were developed based on an extensive review of the literature, previous survey experience, and results from consumer focus groups (also aged 18 to 65). Before survey administration, all items were proofread and tested for comprehension and validity using a small-scale face-to-face pilot. Each of the three main clothing consumption phases (purchase, use and maintenance, discard/disposal) is captured by different measures that cover both general clothing consumption and product category-specific consumption of jeans and t-shirts. Introducing this product category level alongside the domain level helps to validate questions that rely on self-reported behavior. This practice is supported in prior pilot tests in which respondents tended to recall their behavior more precisely when given a concrete clothing category. We chose jeans and t-shirts because these two categories are well known across sexes and cultures and widely purchased in the countries surveyed (e.g., in Sweden, t-shirts and jeans make up $24 \%$ and $19 \%$ of clothing consumption, respectively [1]).

For the purchase phase, the survey includes questions about the number of items bought in the past 3 months and how much was spent on clothing in general or jeans and $t$-shirts in particular. Because we know of no representative spending data for all four countries based on which to develop categories, the questions on expenditure for all clothing items (general, jeans, and $t$-shirt) during the past 3 months were open ended. The responses were then harmonized for cross-country comparability by conversion into euros and adjustment based on the Harmonized Index of Consumer Prices (HCIP) [43]. Using 2015 as the index reference period, set to 100 across all European countries, each respondent's spending was then adjusted using the average HCIP value of the corresponding country from July to September 2016. The survey also asked which brands of clothing the respondents typically purchased, whether budget, casual/medium, or premium (based on [44]); 
which materials (new, conventional; new, organic; reused, recycled; reused, second-hand); and through which acquisition modes.

Information collected for the use and maintenance phase included how many clothing items the respondents possessed at that time, how long they usually keep and wear their clothing, and how often they wear clothes before washing and other laundry related behaviors. Because no general behavior patterns are observable for all clothing product categories in this phase (e.g., laundry behavior differs strongly for a t-shirt vs. a jacket), these items focused on the product category rather than the general fashion domain level (see Table 1, for all clothing consumption related questions and the corresponding answer categories). Lastly, respondents were asked where they discard their unwanted clothes.

Table 1. Measurements by consumption phase.

\begin{tabular}{|c|c|c|}
\hline Question & Items & Answer Categories \\
\hline \multicolumn{3}{|l|}{ Purchase Behavior } \\
\hline $\begin{array}{l}\text { How many items of clothing did you } \\
\text { acquire during the last } 3 \text { months? }\end{array}$ & & $\begin{array}{ll}\text { - } & \text { None } \\
\text { - } & 1-4 \\
\text { - } & 5-9 \\
\text { - } & 10-15 \\
\text { - } & 16-20 \\
\text { - } & 21-25 \\
\text { - } & 26 \text { or more }\end{array}$ \\
\hline $\begin{array}{l}\text { How many of items of the following did } \\
\text { you acquire during the last } 3 \text { months? } \\
\text { (number) } \\
\text { - Jeans } \\
\text { - T-shirt }\end{array}$ & & - $\quad$ Free answer field \\
\hline $\begin{array}{l}\text { How much money did you spend on } \\
\text { clothes/the following within the last } \\
3 \text { months? } \\
\text { - General } \\
\text { - Jeans } \\
\text { - T-shirt }\end{array}$ & & $\begin{array}{l}\text { - Free answer field in } \\
\text { relevant currency }\end{array}$ \\
\hline $\begin{array}{l}\text { At which stores do you typically acquire } \\
\text { your clothes? } \\
\text { Indicate a total sum of } 100 \% \\
\text { - General } \\
\text { - Jeans } \\
\text { - T-shirt }\end{array}$ & $\begin{array}{l}\text { Premium (e.g., Hugo Boss } \\
\text { or Gucci) } \\
\text { - Casual/middle (e.g., Levi's, Esprit, } \\
\text { or Gap) } \\
\text { - } \quad \text { Budget (e.g., H\&M or Forever 21) }\end{array}$ & - $\quad 0 \%-100 \%$ \\
\hline $\begin{array}{l}\text { Of which material is the clothing you } \\
\text { acquire typically made? } \\
\text { Indicate a total sum of } 100 \%\end{array}$ & $\begin{array}{ll}\text { - } & \text { New-conventional material } \\
\text { - } & \text { New-organic material } \\
\text { - } & \text { Reused-recycled material } \\
\text { - } & \text { Reused-second-hand material }\end{array}$ & - $\quad 0 \%-100 \%$ \\
\hline $\begin{array}{l}\text { In the last } 3 \text { months, approximately how } \\
\text { frequently did you use the listed modes to } \\
\text { acquire new clothes? }\end{array}$ & $\begin{array}{ll}\text { - } & \text { High street } \\
\text { - } & \text { Shopping mall } \\
\text { - } & \text { Online shopping } \\
\text { - } & \text { Mail-order } \\
\text { - } & \text { Small boutiques } \\
\text { - } & \text { Second-hand (e.g., shop, flea } \\
& \text { market, eBay) } \\
\text { - } & \text { Supermarket } \\
\text { - } & \text { Swap (i.e., exchange/barter } \\
& \text { of clothes) } \\
\text { - } & \text { Other: (Please indicate) }\end{array}$ & $\begin{array}{ll} & \\
\text { - } & \text { Never } \\
\text { - } & 1-2 \text { times } \\
\text { - } & 3-5 \text { times } \\
\text { - } & 6-10 \text { times } \\
\text { - } & 11-15 \text { times } \\
\text { - } & \text { More than } 15 \text { times }\end{array}$ \\
\hline
\end{tabular}


Table 1. Cont.

\begin{tabular}{|c|c|c|}
\hline Question & Items & Answer Categories \\
\hline \multicolumn{3}{|l|}{ Use and Maintenance Behavior } \\
\hline $\begin{array}{l}\text { How many items do you have of the } \\
\text { following? (number) } \\
\text { Jeans } \\
\text { - T-shirt }\end{array}$ & & $\begin{array}{l}\text { Free answer field for } \\
\text { each jeans and t-shirt }\end{array}$ \\
\hline $\begin{array}{l}\text { How long do you usually keep the } \\
\text { following clothing items before discarding } \\
\text { (disposing) it? } \\
\text { - Jeans } \\
\text { - T-shirt }\end{array}$ & & $\begin{array}{l}\text { - } \quad \text { Less than } 6 \text { months } \\
\text { - } \quad \text { Less than a year } \\
\text { - } 1-2 \text { years } \\
\text { - } \quad 3-4 \text { years } \\
\text { - } \quad 5 \text { years or more }\end{array}$ \\
\hline $\begin{array}{l}\text { How many times do you wear an average } \\
\text { pair of jeans or t-shirt from your wardrobe? } \\
\text { - Jeans } \\
\text { - T-shirt }\end{array}$ & & $\begin{array}{ll}\text { - } & \text { Very rarely } \\
\text { (once a year or less) } \\
\text { - } & \text { Rarely (less than once } \\
\text { every } 3 \text { months) } \\
\text { - } & \begin{array}{l}\text { Sometimes } \\
\text { (at least once every }\end{array} \\
\text { other month) } \\
\text { - Often } \\
\text { (at least once a month) } \\
\text { - } \quad \begin{array}{l}\text { Very often } \\
\text { (at least once a week) }\end{array}\end{array}$ \\
\hline $\begin{array}{l}\text { How many times do you wear the following } \\
\text { clothing items on average before washing? }\end{array}$ & & $\begin{array}{l}\text { - Free answer field for } \\
\text { each jeans and t-shirt }\end{array}$ \\
\hline $\begin{array}{l}\text { At which temperature do you wash? } \\
\text { - Jeans } \\
\text { T-shirt }\end{array}$ & & $\begin{array}{ll}\text { - } & 20^{\circ} \mathrm{C} \\
\text { - } & 30^{\circ} \mathrm{C} \\
\text { - } & 40^{\circ} \mathrm{C} \\
\text { - } & 50{ }^{\circ} \mathrm{C} \\
\text { - } & 60{ }^{\circ} \mathrm{C} \\
\end{array}$ \\
\hline $\begin{array}{l}\text { Do you use detergent when washing? } \\
\text { Do you use softener when washing? } \\
\text { - Jeans } \\
\text { - T-shirt }\end{array}$ & & $\begin{array}{ll}\text { - } & \text { No } \\
\text { - } & \text { Yes, non-eco } \\
\text { - } & \text { Yes, eco } \\
\end{array}$ \\
\hline Do you use the dryer after washing? & & $\begin{array}{ll}\text { - } & \text { Yes } \\
\text { - } & \text { No } \\
\end{array}$ \\
\hline \multicolumn{3}{|l|}{ Discard Behavior } \\
\hline $\begin{array}{l}\text { How do you typically discard your } \\
\text { unwanted clothing? } \\
\text { Indicate a total sum of } 100 \% \\
\text { - General } \\
\text { - Jeans } \\
\text { - T-shirt }\end{array}$ & $\begin{array}{l}\text { - Second-life (e.g., donating, } \\
\text { recycling programs, flea-market, } \\
\text { passing on to family) } \\
\text { - } \quad \text { Down-cycling (e.g., use as rags) } \\
\text { - Trash }\end{array}$ & - $\quad 0 \%-100 \%$ \\
\hline
\end{tabular}

The survey also included a set of questions relating to environmentally friendly clothing consumption behaviors, measured on the environmental apparel consumption (EAC) scale [45], which assesses the frequency of such behaviors as purchasing recycled or second-hand apparel or purposely selecting energy efficient or less polluting clothing products (see Table 2). The EAC measure is a mean score calculated over all eight scale items. The survey also asked, again on the product category-specific level (jeans and t-shirts), how much the respondents value second-hand clothing items or those made from recycled or organic materials compared to new products made of conventional materials. Lastly, it recorded respondents' past and future intended use of alternative business models (developed in collaboration with industry experts), such as clothes leasing, libraries, or in-store repair services. 
Table 2. Measurements of environmentally friendly clothing consumption behavior.

\begin{tabular}{|c|c|c|}
\hline Question & Items & Answer Categories \\
\hline $\begin{array}{l}\text { Environmental Apparel } \\
\text { Consumption (EAC) } \\
\text { In the following, please indicate } \\
\text { what applies to you. } \\
\text { When acquiring clothing items, I ... }\end{array}$ & $\begin{array}{l}\text { - Buy clothes with environmentally friendly } \\
\text { - } \quad \text { buy clothing or packaging techniques } \\
\text { natural fibers } \\
\text { - } \quad \text { Buy second-hand clothes } \\
\text { Buy clothes with low impact or no } \\
\text { dye processing } \\
\text { - Select clothes that you can wear over a } \\
\text { longer term compared to trendy clothes that } \\
\text { go out of style quickly } \\
\text { - Purposely select fabrics that require cooler } \\
\text { washing temperature, shorter drying time, } \\
\text { or less ironing } \\
\text { Avoid clothes products because of } \\
\text { environmental concerns } \\
\text { Buy clothes made from recycled material }\end{array}$ & $\begin{array}{ll}\text { - } & \text { Very rarely or never } \\
\text { - } & \text { Rarely } \\
\text { - } & \text { Sometimes } \\
\text { - } & \text { Often } \\
\text { - } & \text { Very often or always }\end{array}$ \\
\hline $\begin{array}{l}\text { If a pair of new conventional } \\
\text { jeans/a new conventional t-shirt is } \\
100 \% \text {, how much would you pay } \\
\text { for exactly the same pair of } \\
\text { Indicate by a slider a higher or lower } \\
\text { value compared to the } \\
\text { conventional product }\end{array}$ & $\begin{array}{ll}\text { - } & \text { Recycled jeans/t-shirt } \\
\text { - } & \text { Second-hand jeans/t-shirt } \\
\text { - } & \text { New organic material jeans/t-shirt }\end{array}$ & - $\quad \operatorname{Low}(0 \%)-\operatorname{High}(200 \%)$ \\
\hline $\begin{array}{l}\text { Have you previously used } \\
\text { the following ... }\end{array}$ & $\begin{array}{ll}\text { - } & \text { Fashion leasing (e.g., similar to car leasing) } \\
\text { - } & \text { Traditional repair services (e.g., mending } \\
\text { clothes yourself, tailor) } \\
\text { - } \quad \text { Reselling clothes online (e.g., eBay) } \\
\text { - } \quad \text { wwap markets (swapping clothes } \\
\text { without payment) } \\
\text { - } \quad \text { Repair services in-store (e.g., Nudie Jeans) } \\
\text { - Fashion rental (e.g., special occasion like } \\
\text { weddings or carnival) } \\
\text { - Clothing libraries (e.g., similar to } \\
\text { book libraries) } \\
\text { Incentivized take back services (e.g., leaving } \\
\text { clothing for recycling in exchange for a } \\
\text { voucher or a buy-back program) }\end{array}$ & $\begin{array}{ll}\text { - } & \text { Yes } \\
\text { - } & \text { No }\end{array}$ \\
\hline $\begin{array}{l}\text { Could you imagine using the } \\
\text { following in the future: } \\
\text { Indicate on a percentile slider } \\
\text { from } 0-100\end{array}$ & $\begin{array}{ll}\text { - } & \text { Fashion leasing (e.g., similar to car leasing) } \\
\text { - } & \text { Traditional repair services (e.g., mending } \\
\text { clothes yourself, tailor) } \\
\text { - } \quad \text { Reselling clothes online (e.g., eBay) } \\
\text { - } \quad \text { wwapping markets (swapping clothes } \\
\text { without payment) } \\
\text { - } \quad \text { Repair services in-store (e.g., Nudie Jeans) } \\
\text { - Fashion rental (e.g., special occasion like } \\
\text { weddings or carnival) } \\
\text { - Clothing libraries (e.g., similar to } \\
\text { book libraries) } \\
\text { Incentivized take back services (e.g., leaving } \\
\text { clothing for recycling in exchange for a } \\
\text { voucher or a buy-back program) }\end{array}$ & $\begin{array}{ll}\text { - } & \text { Very unlikely }(0) \\
\text { - } & \text { Neutral }(50) \\
\text { - } & \text { Very likely }(100)\end{array}$ \\
\hline
\end{tabular}

The final section of the survey collected sociodemographic data such as sex, age in years, country, and income, which later we divide for comparability into 11 categories based on corresponding national statistics (Eurostat for Germany, Poland and Sweden; U.S. Census Bureau for the U.S.). The income calculation algorithm, which uses the 2014 statistic for the monthly net income of the 18-64 age group in each country, ensures cross-country comparability through the following four-step process: (1) identifying the median income per country and using this as the lower boundary of the middle-income category; (2) defining the upper boundary of the lowest category as the poverty line 
for singles (i.e., $60 \%$ of the median income of a single household); (3) defining the lower boundary of the upper level as approximately 2.5 times the median income; and (4) spreading the intervals for the 11 categories evenly.

\subsection{Analytic Strategy}

To assess current clothing consumption behavior, we created artificial consumer segments by employing a cluster analysis. However, because sociodemographics seemed to have lost their predictive power through consumer fragmentation [46], we achieved our main aim of identifying consumption patterns and their potential relations to different related environmental aspects by eschewing the socioeconomic clustering variables common in segmentation strategies, as well as values or attitudes toward a product domain, general lifestyle, or actual reported behavior. Rather, we defined our segments based on purchasing behavior, building the different segments to sort the heterogeneous sample into more homogenous subgroups whose members resemble each other on the clustering variables. At the same time, to account for as many intergroup differences as possible, we identified our consumer groups based on the amount and type of clothing bought and then compared them based on both purchasing and environmentally related behaviors across the consumption phases. This process enabled us to compare, for example, high volume and budget brand buying consumers with low volume premium buying consumers with regard to discard behavior.

To achieve our aim, we combined domain specific (general fashion) and product category-specific (jeans and t-shirts) variables [47]. As the segmentation base, we included on the domain-specific level only the following purchase characteristics: material purchased (new, conventional; new, organic; recycled; and second-hand) and acquisition mode, divided into first market acquisitions, including high street, shopping mall, online shopping, mail order, small boutiques, and supermarket; and second market acquisitions, including second-hand purchases and swapping (see also Table 1). We then assessed the type of brands purchased (budget, casual/medium and premium), the number of purchased items, and spending over the last 3 months on both the domain- and product category-specific levels. To determine the number of clusters, we employed a hierarchical cluster analysis with the squared Euclidean distance as the distance measure and then used Ward's algorithm to link consumers. In line with the Duda-Hart stopping rule, we created five clusters by running a k-means clustering analysis on a 3984 respondent sample determined by missing values in the segmentation base variables $(n=633)$ and case-wise deletion. The resulting segments are: (1) low consumption—budget brands; (2) low consumption—casual/medium brands; (3) medium consumption—budget brands; (4) medium consumption—casual/medium brands; and (5) high consumption-casual/medium and premium brands.

We then compared these five consumer segments on sociodemographics, use and maintenance behavior, discard behavior, and environmentally related behavior employing either ANOVA or Kruskal-Wallis equality-of-populations rank tests dependent on the measurement level and variable distribution across segments. In presenting the results, instead of $p$-values, we report only the differences that are statistically significant (the group comparison results are available from the authors upon request). After first describing the consumer segments' demographic characteristics and reported purchase behaviors, which serve as the segmentation base, we compare their use and maintenance, and discard behaviors. We then investigate intersegmental differences in environmentally friendly clothing consumption behavior.

\section{Results}

\subsection{Consumer Segments and their Purchasing Behavior}

The descriptive statistics for the purchasing behavior of the overall sample and consumer segments are presented in Table 3, which also gives the size of the individual segments. Over the course of three months, the average consumer purchases an average 5.9 clothing items, of which 2.1 are 
t-shirts (costing an average of 29 euro for two) and 0.9 is a pair of jeans (around 33 euro), for an overall cost of approximately 153 euro (column 1). Purchasing occurs about twice in the three-month period, mostly in shopping malls and online, followed by second-hand (1.4 times) and high street (1.1 times) shops, with swapping as the least used acquisition mode (column 1). Approximately $58.7 \%$ of these clothes are from budget brands, $33.5 \%$ from casual/medium brands, and only $7.8 \%$ from premium brands. The most purchased clothing material, at $61.1 \%$, is new conventional fabric, followed by new organic at $17.8 \%$, second-hand clothing at $13.2 \%$, and recycled materials at only $7.8 \%$.

This purchasing behavior, however, differs significantly across consumer segments: whereas Segments 1 and 2 buy only a little clothing, Segments 3 and 4 purchase an above average number of items, and Segment 5 engages in heavy clothing consumption of luxury items. At the low end of this spectrum, Segment 1 (1712 respondents) consumes little and prefers budget outlets, meaning that a large share of consumers (over $43.0 \%$ of the full sample) purchase only a limited amount of clothing for relatively little money. At the other extreme, Segment 5 (100 respondents) has a high clothing purchase profile with high spending on mainly casual/medium and premium clothing; however, this segment accounts for only $2.5 \%$ of the full sample. In the more moderate range, Segment 3 , comprising around $20.8 \%$ of the full sample (828 respondents), engages in relatively high clothing consumption segment but buys from budget outlets.

Although the number of items purchased is very similar for the two lowest consumer segments (see Table 3, columns 2 and 3), they differ significantly in their spending habits and brand selection. Whereas Segment 1 spends around 58 euro on 4.4 clothing items, Segment 2 spends around 78 euro on 4.3 items. Similarly, whereas Segment 3 purchases around 8.4 items, Segment 4 buys around 10.9 items at a significantly higher per item price for a higher total outlay. These differences in money spent are mirrored in brands chosen, with Segments 2 and 4 purchasing less from budget brands and significantly more from casual/medium brands (columns 2 and 4). In fact, Segment 4 consumers have a high consumption of casual/medium and premium brands, buying about 13.6 clothing items for 950 euro over the three-month period, about $41.0 \%$ from casual/medium brands and $36.4 \%$ from premium brands. Segment 5 also reported the highest usage frequencies for all acquisition modes, over five times each in three months for shopping malls and online shopping, three times for mail order (by far the highest) and 2.4 times for second-hand outlets. As regards acquisition modes, whereas Segments 4 and 5 account for a higher share of small boutiques, the middle consumer segments engage in a higher share of online shopping. Second-hand outlets, however, have the relatively highest share among Segment 1 consumers, the low consumption budget buyers, which might explain their low expenditure on clothing purchases. As a result, Segment 1 buys the highest proportion of second-hand material, at $16.2 \%$, while Segments 4 and 5 purchase the highest share of clothing made of new organic material, at $23.5 \%$ and $22.1 \%$, respectively (see Table 3 ). Conventional material is dominant in all consumer segments.

The segments also differ in their demographics, especially country of residence (see Figure 1). Polish consumers account for the highest share of Segment $1(35.2 \%)$ but lowest share of Segment 5 $(4.0 \%)$, perhaps because of their limited purchasing power compared to consumers from the other participating countries. Germans make up around 19.9\% of Segment 1 but account for $27.7 \%$ or above of the other segments. Together with Germans, Swedes, at over 30\%, make up the highest share of the Segment 3 medium consumption budget consumers. U.S. consumers, in contrast, make up only $21.4 \%$ of the Segment 3 budget shoppers but account for a relatively high share (37.0\%) of the high consumption purchasers of casual/medium and premium brands. Hence, even after expenditures are harmonized, the consumer segments are substantially differentiated by nationality. 
Table 3. Descriptive statistics for segmentation variables.

\begin{tabular}{|c|c|c|c|c|c|c|c|c|c|c|c|c|}
\hline & \multicolumn{2}{|c|}{ All } & \multicolumn{2}{|c|}{$\begin{array}{c}\text { Segment } 1 \\
\text { Low-Budget }\end{array}$} & \multicolumn{2}{|c|}{$\begin{array}{c}\text { Segment } 2 \\
\text { Low-Casual }\end{array}$} & \multicolumn{2}{|c|}{$\begin{array}{c}\text { Segment } 3 \\
\text { Medium-Budget }\end{array}$} & \multicolumn{2}{|c|}{$\begin{array}{c}\text { Segment } 4 \\
\text { Medium-Casual }\end{array}$} & \multicolumn{2}{|c|}{$\begin{array}{c}\text { Segment } 5 \\
\text { High-Premium }\end{array}$} \\
\hline & Mean & (SD) & Mean & (SD) & Mean & (SD) & Mean & (SD) & Mean & (SD) & Mean & (SD) \\
\hline \multicolumn{13}{|c|}{ Items purchased last 3 months (number) } \\
\hline General fashion & 5.86 & (5.14) & 4.38 & $(4.01)$ & 4.25 & (3.63) & 8.39 & (5.23) & 10.90 & $(6.37)$ & 13.63 & (7.24) \\
\hline Jeans & 0.87 & $(1.29)$ & 0.58 & $(0.98)$ & 0.75 & $(1.18)$ & 1.17 & $(1.38)$ & 1.72 & (1.67) & 2.42 & $(2.28)$ \\
\hline T-shirts & 2.12 & (2.72) & 1.59 & $(2.35)$ & 1.87 & $(2.35)$ & 2.65 & (2.81) & 3.97 & (3.77) & 4.33 & $(3.90)$ \\
\hline \multicolumn{13}{|c|}{ Expenditures last 3 months (€, harmonized HCIP) ${ }^{1}$} \\
\hline General fashion & 153.43 & $(182.84)$ & 57.87 & $(44.28)$ & 78.38 & $(47.63)$ & 244.45 & $(57.52)$ & 481.90 & $(97.86)$ & 950.83 & $(83.17)$ \\
\hline Jeans & 33.38 & $(77.93)$ & 10.58 & (20.12) & 23.28 & (39.38) & 45.90 & $(63.00)$ & 114.08 & (140.20) & 209.53 & $(270.57)$ \\
\hline T-shirts & 29.14 & (63.09) & 10.59 & (16.24) & 22.06 & $(33.50)$ & 39.56 & (46.73) & 96.32 & (117.00) & 154.39 & (228.64) \\
\hline \multicolumn{13}{|l|}{ Brand $(\%$, accumulates to $100 \%)$} \\
\hline General fashion: premium & 7.81 & (15.85) & 1.81 & $(6.01)$ & 9.51 & (16.55) & 10.57 & $(17.81)$ & 20.00 & (21.89) & 36.36 & $(24.86)$ \\
\hline General fashion: casual/medium & 33.49 & (29.78) & 13.94 & $(19.23)$ & 54.78 & $(27.56)$ & 41.01 & $(28.01)$ & 47.00 & $(23.98)$ & 40.97 & (19.63) \\
\hline General fashion: budget & 58.70 & $(34.52)$ & 84.26 & $(21.05)$ & 35.72 & $(27.88)$ & 48.41 & $(32.21)$ & 33.00 & $(26.09)$ & 22.67 & $(17.69)$ \\
\hline Jeans: premium & 7.26 & $(17.45)$ & 0.97 & $(4.11)$ & 9.36 & $(18.64)$ & 9.80 & $(19.84)$ & 20.54 & $(26.41)$ & 35.57 & (30.54) \\
\hline Jeans: casual/medium & 36.82 & $(36.09)$ & 10.27 & (17.55) & 69.68 & $(27.89)$ & 43.89 & (34.62) & 50.32 & (32.54) & 43.67 & $(29.81)$ \\
\hline Jeans: budget & 55.91 & $(39.68)$ & 88.76 & (18.66) & 20.95 & $(23.68)$ & 46.31 & $(37.78)$ & 29.14 & $(32.01)$ & 20.76 & $(25.39)$ \\
\hline T-shirt: premium & 6.30 & (15.73) & 0.91 & $(5.53)$ & 7.88 & $(16.26)$ & 8.57 & $(17.93)$ & 18.06 & (23.13) & 30.88 & $(29.27)$ \\
\hline T-shirt: casual/medium & 31.95 & $(33.61)$ & 8.09 & $(14.31)$ & 60.72 & $(30.41)$ & 38.49 & $(32.31)$ & 46.21 & (30.68) & 39.02 & $(28.45)$ \\
\hline T-shirt: budget & 61.75 & (37.66) & 91.00 & (15.82) & 31.40 & $(29.67)$ & 52.95 & $(36.41)$ & 35.73 & (32.46) & 30.10 & (31.00) \\
\hline \multicolumn{13}{|l|}{ Acquisition mode $^{2}$} \\
\hline High street & 1.10 & $(2.00)$ & 0.71 & $(1.32)$ & 0.84 & $(1.67)$ & 1.44 & $(2.09)$ & 2.49 & $(3.30)$ & 3.96 & $(4.00)$ \\
\hline Shopping mall & 2.09 & $(2.79)$ & 1.65 & (2.40) & 1.74 & $(2.34)$ & 2.48 & $(2.70)$ & 3.92 & $(4.28)$ & 5.01 & $(4.47)$ \\
\hline Online shopping & 2.10 & (3.02) & 1.39 & $(2.33)$ & 1.74 & (2.44) & 3.03 & (3.47) & 4.07 & $(4.36)$ & 4.97 & (4.55) \\
\hline Mail order & 0.84 & $(2.03)$ & 0.58 & (1.43) & 0.61 & (1.51) & 1.18 & (2.49) & 1.63 & $(3.21)$ & 2.82 & $(4.28)$ \\
\hline Small boutiques & 0.72 & $(1.73)$ & 0.44 & (1.18) & 0.61 & (1.55) & 0.93 & (1.99) & 1.56 & $(2.45)$ & 2.82 & (3.64) \\
\hline Second-hand & 1.41 & $(2.90)$ & 1.61 & (3.07) & 1.21 & $(2.78)$ & 1.14 & (2.44) & 1.49 & $(2.87)$ & 2.24 & (3.96) \\
\hline Supermarket & 0.84 & $(2.12)$ & 0.80 & (1.78) & 0.75 & $(2.24)$ & 0.75 & (1.86) & 1.40 & $(3.20)$ & 1.91 & (3.63) \\
\hline Swapping & 0.36 & $(1.58)$ & 0.23 & $(1.20)$ & 0.38 & (1.72) & 0.33 & (1.33) & 0.78 & $(2.32)$ & 1.53 & (3.46) \\
\hline \multicolumn{13}{|c|}{ Material purchased (\%, accumulates to $100 \%)$} \\
\hline New conventional & 61.13 & (32.70) & 62.03 & $(34.31)$ & 60.13 & (32.69) & 61.93 & (30.12) & 57.70 & $(30.81)$ & 59.16 & (29.37) \\
\hline New organic & 17.81 & (20.52) & 14.14 & (19.70) & 19.39 & (20.69) & 20.77 & (20.62) & 24.04 & (21.19) & 22.14 & (19.10) \\
\hline Reused-recycled & 7.82 & (12.65) & 6.73 & (12.73) & 8.48 & (13.36) & 8.53 & (11.88) & 9.52 & (11.64) & 9.03 & (10.82) \\
\hline Reused-secondhand & 13.24 & (22.35) & 17.10 & (26.44) & 12.00 & (20.63) & 8.78 & (15.55) & 8.74 & $(15.04)$ & 9.67 & (16.04) \\
\hline Observations & 3984 & & 1712 & & 1073 & & 828 & & 271 & & 100 & \\
\hline
\end{tabular}

${ }^{1}$ The expenditures, which are from September 2016, are converted into euro exchange rates and harmonized on clothing prizes across countries using the Harmonized Index of Consumer Prices (HCIP). The baseline is the averaged HCIP for the period June-August 2016 with the average clothing prices in Europe in 2015 as the reference (100); ${ }^{2}$ Acquisition mode is measured in times over the last three months. 
Country by consumer segment

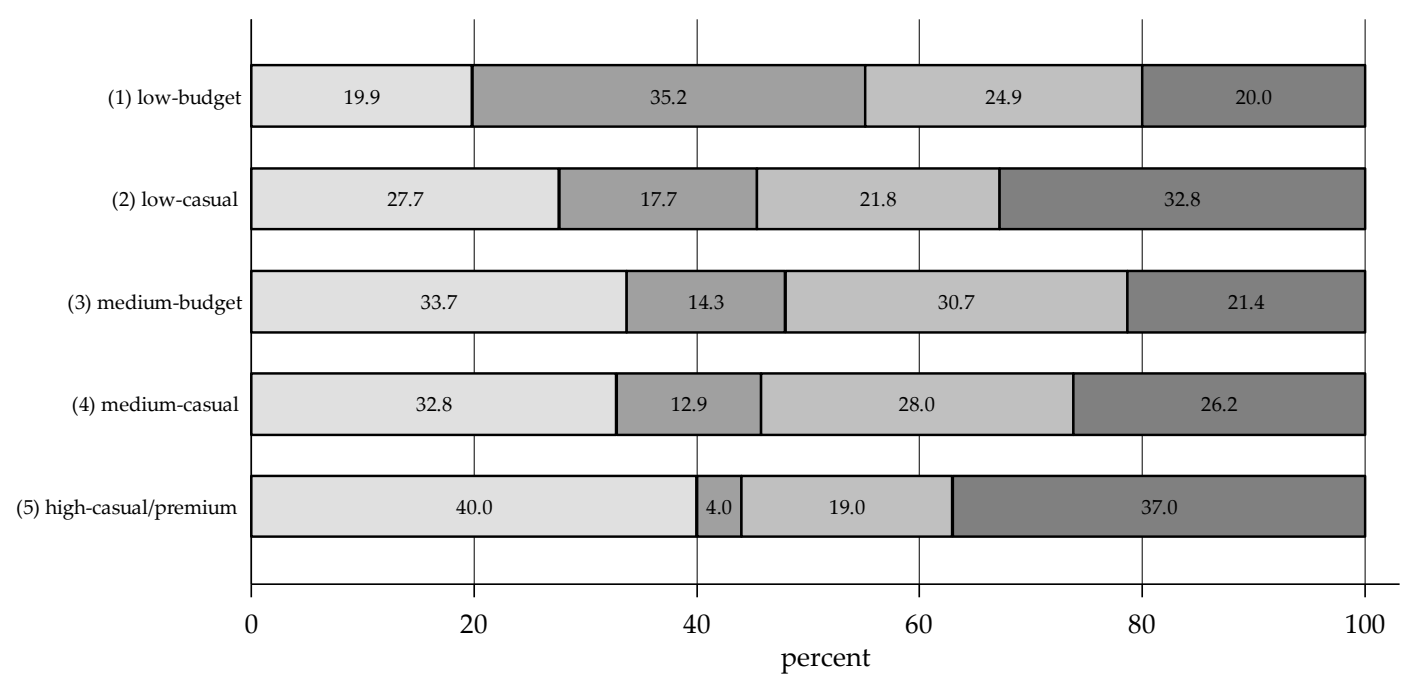

Note: mean;

accumulates to $100 \%$

$$
\square \text { Germany } \square \text { Poland } \square \text { Sweden } \square \text { U.S. }
$$

Figure 1. Country by consumer segment.

Although the age distribution is similar across all five segments, one gender difference is notable: whereas female consumers make up over $60 \%$ of the largest segment (the budget buyers in Segment 1), male consumers account for the majority (57\%) of the 100 (medium and premium) consumers in Segment 5. As regards the final sociodemographic variable of monthly net income, (see Figure 2), Segment 1 buyers have the lowest median income of all consumer segments, while the median income of Segment 2 and 3 consumers fall into category 5 . This latter observation is interesting given that although consumers in both Segments ( 2 and 3 ) spend similar amounts, Segment 3 consumers buy twice as many clothing items for the money as Segment 2 buyers: 214 euro for 8.4 budget brand items versus 93 euro for 4.2 casual/medium brand items, respectively (see Appendix A Table A1 for the descriptive statistics for all sociodemographic variables).

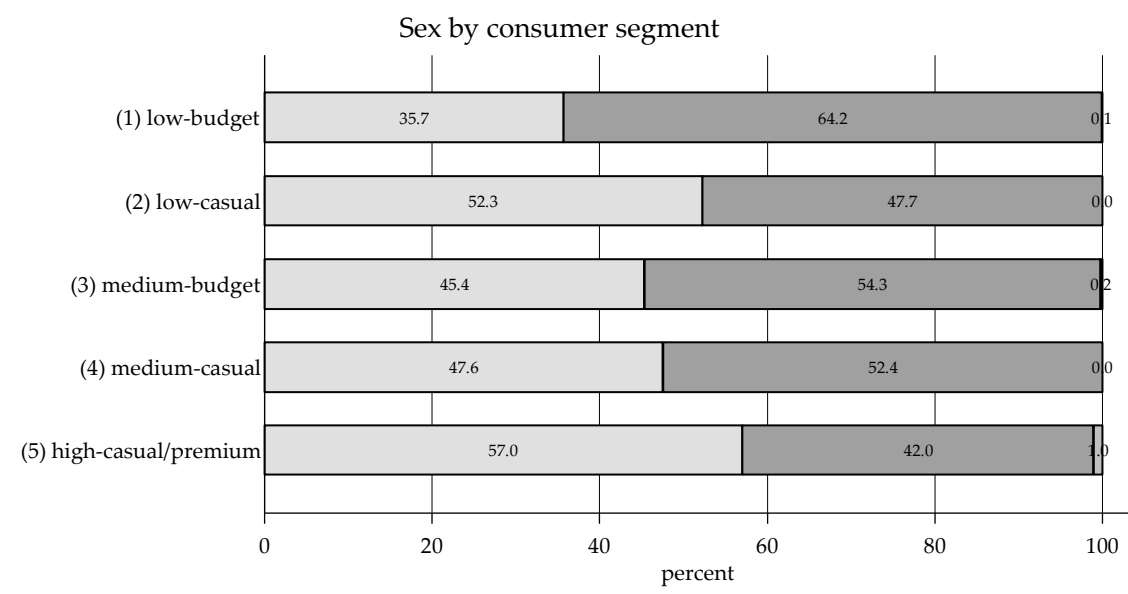

Note: mean;
accumulates to $100 \%$

$\square$ male $\square$ female $\square$ other

(a)

Figure 2. Cont. 


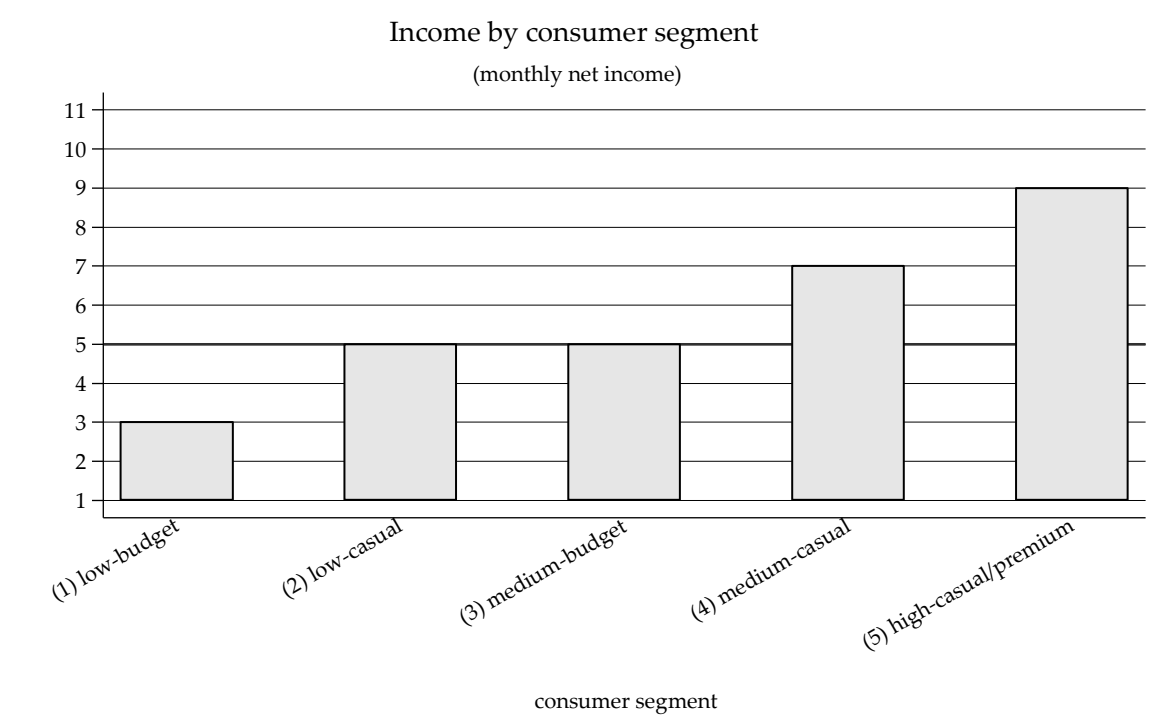

Note: income in 11 categories;
overall median income $=5$

(b)

Figure 2. Demographics by consumer segment. (a) Sex by consumer segment (b) Income by consumer segment.

\subsection{Use and Maintenance Behavior}

Based on our survey participant responses, the average consumer possesses $18.6 \mathrm{t}$-shirts $(S D=12.72)$ and six pairs of jeans $(S D=4.90)$ intended for wear at least monthly for $3-4$ years. In fact, as Figure 3 shows, Segments 4 and 5 own significantly more than any other segment-about 22.9 and 24.4 t-shirts, and 8.5 and 11 pairs of jeans, respectively-which is not surprising given their high consumption during the purchasing phase. The segments exhibit no differences, however, in the time clothes are kept before being discarded and/or the frequency of wearing each clothing item, which violates our expectations of differences based on different purchasing behaviors (e.g., the likelihood that Segment 5 consumers, having purchased so many clothing items, would wear them less often).

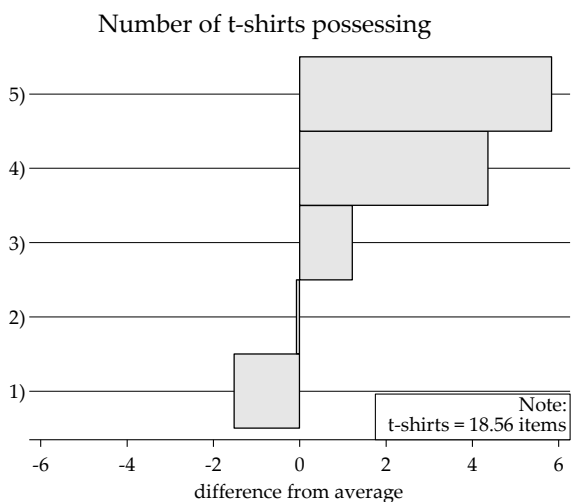

(a)

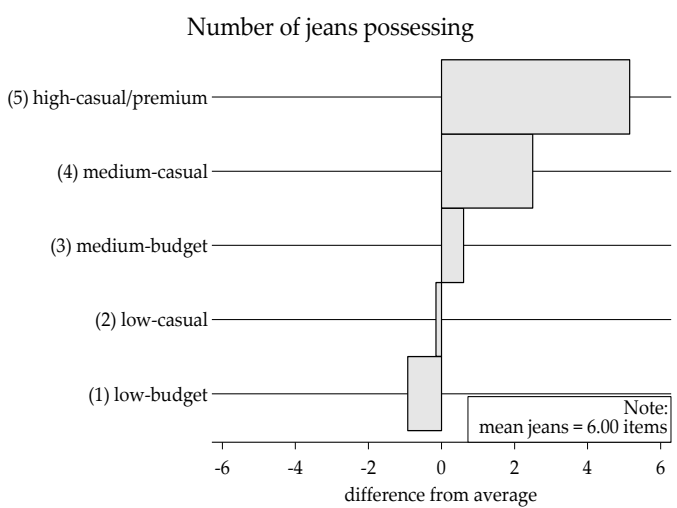

(b)

Figure 3. Number of jeans and t-shirts owned by consumer segment. (a) Number of $t$-shirts processing; (b) Number of jeans processing.

Although the average consumer wears a pair of jeans about 8.2 times and a t-shirt about 2.3 times before washing, we find one significant difference in this number of wears: Segment 1 wears jeans and t-shirts more often (at 8.7 and 2.5 times, respectively) before washing than Segments 4 and 5 (at 7.3 and 2.0 times, and 6.4 and 1.9 times, respectively). All consumer segments, however, exhibit similar 
washing behavior, using an average temperature of $40^{\circ} \mathrm{C}$, regardless of whether jeans or t-shirt, with a small number $(3.2 \%)$ using no detergent, the majority (65.4\%) using a non-eco detergent, and just under a third (31.3\%) using an eco-detergent. Around $50 \%$ of the consumers use softener, about $14 \%$ of which is eco-softener, but only about $30 \%$ use a dryer. No intersegmental differences are observable, however, in washing and drying behavior (see Appendix A Table A2 for all descriptive statistics for this phase).

\subsection{Discard Behavior}

Our survey respondents reported giving about $70.7 \%$ of their discarded clothes a second life by donating, recycling, selling at flea markets, or passing them on to family members. Disposal of the remaining $30 \%$ is equally distributed between down-cycling (e.g., using clothes as rags) and putting them in the trash. When asked specifically about discarding jeans and $\mathrm{t}$-shirts, participants responded that $\mathrm{t}$-shirts are less likely $(52.2 \%)$ to receive a second life but are more often down-cycled $(27.8 \%)$ or trashed $(20.1 \%)$. Jeans, on the other hand, are less often down-cycled $(14.7 \%)$. Interestingly, not only did respondents report a lower share of second life clothes when asked about a specific product category rather than clothes in general, but the Segment 5 high consumers of casual/medium and premium brands indicated no higher share of second life for their unwanted clothes than the other segments (see Appendix A Table A3 for all corresponding descriptive statistics).

\subsection{Environmentally Friendly Clothing Consumption Behavior}

To assess environmentally friendly clothing consumption behavior, our analysis included measurements of environmental apparel consumption, the monetary value consumers attribute to different clothing materials (with new conventional material as a reference point), and the previous and future intended use of select alternative business models (see Appendix A Table A4 for the full descriptive statistics). Here, the mean environmental apparel consumption is $2.68(S D=0.80)$ on a 5-point Likert scale (with a higher value indicating more environmental apparel consumption). Our comparison of consumer segments (Figure 4) reveals that Segments 4 and 5 reported engaging in environmental apparel consumption significantly more often.

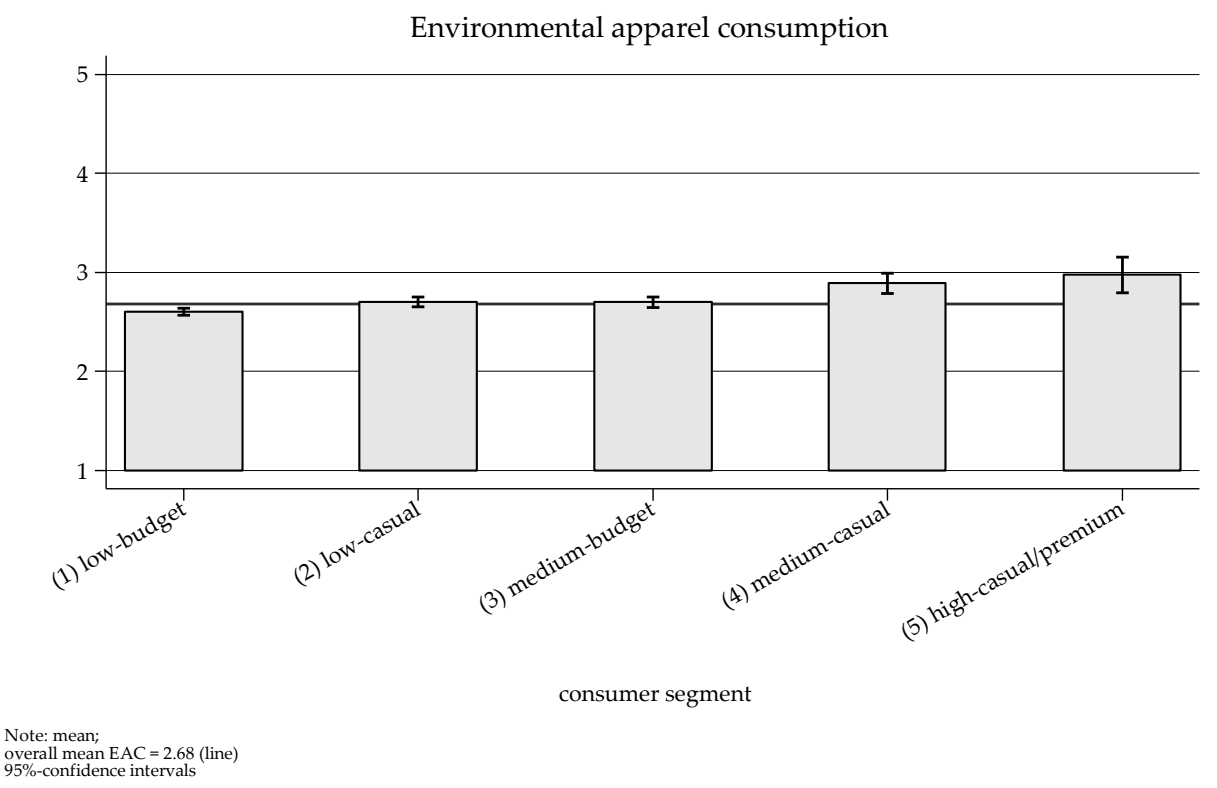

Figure 4. Environmental apparel consumption by consumer segment.

The value that the average consumer attributes to a pair of jeans and t-shirts made of recycled materials is $64.8 \%$ and $62.0 \%$, respectively, of that for these same two items made of new conventional 
materials. As expected, second-hand clothing is valued even lower, at $36.5 \%$ of the value attributed to a pair of jeans made of conventional material. The outcomes are similar for second-hand t-shirts, which are valued at $40.9 \%$ of a new conventional t-shirt. The only materials that match the attributed value of new conventional materials are new organic materials, but even these do not exceed the reference value. Hence, if we interpret the attributed value as an indicator for willingness to pay, we could conclude that consumers are on average unwilling to pay more for clothing made of any other material than the conventional materials dominating the market today. A comparison across consumer segments (see Figure 5), however, reveals an interesting difference: Segment 5's valuation (at 11.0\%) of organic material (in this case, jeans) over conventional material is higher than that of any other segment. Segment 1, in contrast, attributes a lower value than either Segment 3 or 5 to both jeans and $\mathrm{t}$-shirts made of organic cotton.

T-shirt

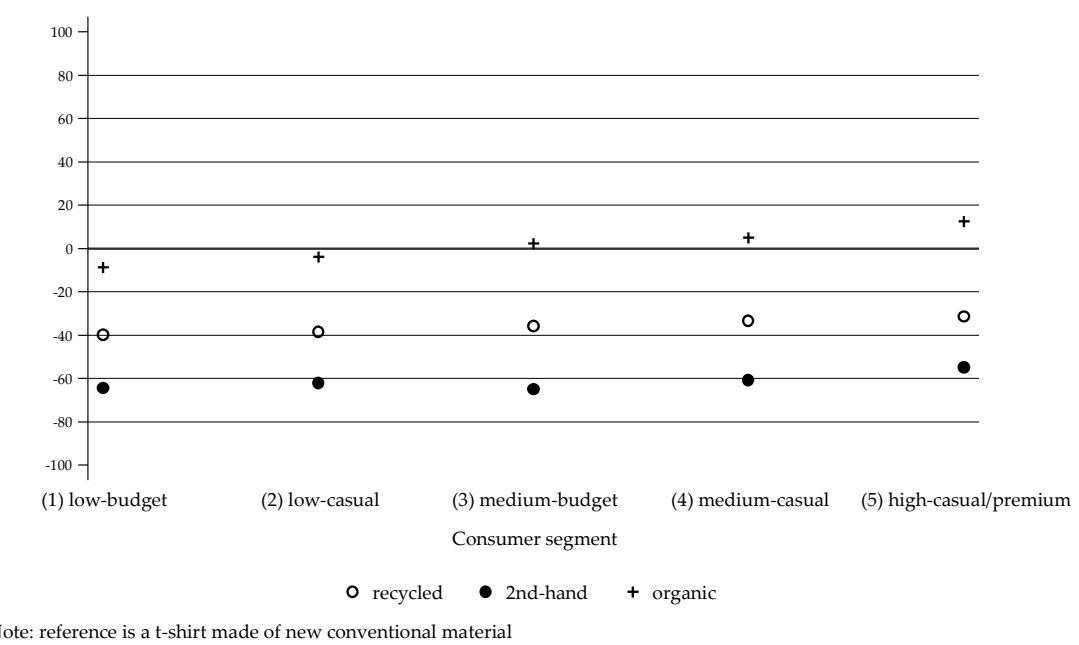

(a)

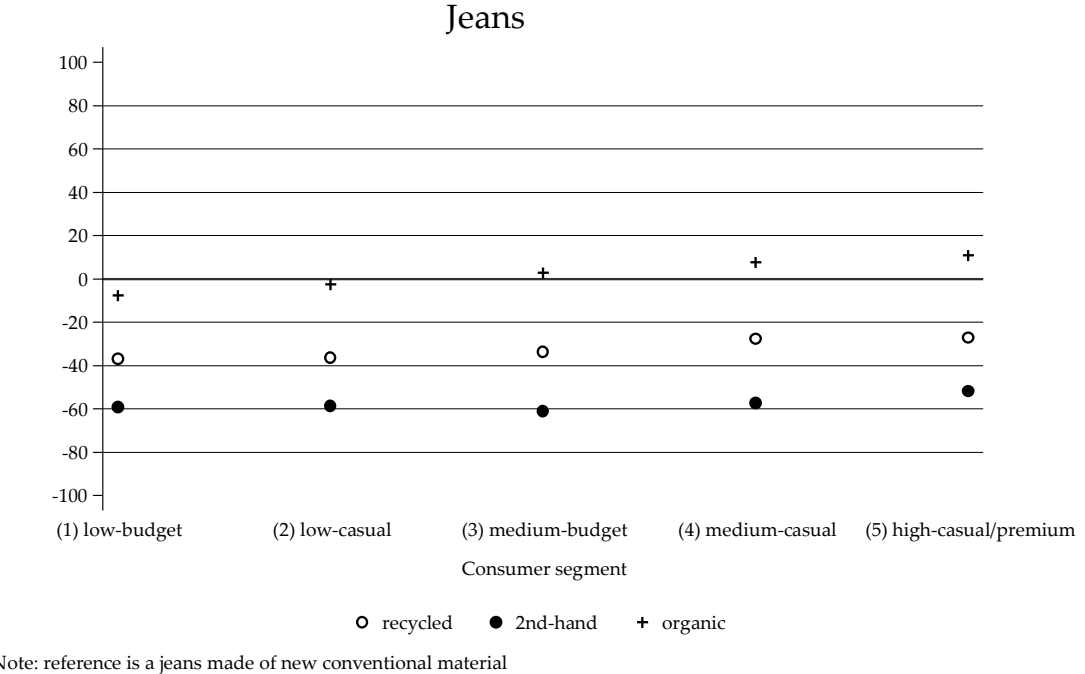

(b)

Figure 5. Attributed value of material by consumer segment. (a) T-shirts; (b) Jeans.

The most used alternative business models among the consumers surveyed were reselling clothes online $(41.1 \%)$ and traditional repair services $(64.3 \%)$, although $10 \%-20 \%$ of the consumers also reported using fashion rentals (17.3\%), swap markets $(16.5 \%)$, incentivized take-back schemes $(14.4 \%)$, and in-store repair services (11.7\%). Only $4.6 \%$ and $3.7 \%$, respectively, of the full consumer sample, however, had used the more niche business models of clothing libraries and fashion leasing, with $17.0 \%$ 
and $10 \%$ of Segments 5 and 4, respectively, but under $5 \%$ of the other segments indicating previous use of fashion libraries. In fact, Segment 5 , followed by Segment 4 , accounts for significantly higher use of the alternative business models included in the survey, with the other three segments differing little from each other.

As regards future intended use of alternative business models, the average consumer seems generally unsupportive, indicating only positive intentions for traditional repair services, reselling clothes online, and incentivized take-back schemes. Comparing across segments reveals that Segments 1 to 4 are less likely than Segment 5 to use clothing libraries, fashion rentals, and fashion leasing (see Figure 6), while Segments 4 and 5 have a higher likelihood of using traditional and in-store repair services, perhaps reflecting their prior experience with them. All segments other than Segment 2 show a general positive future intention for online reselling platforms, incentivized take-back schemes, and traditional repair services.

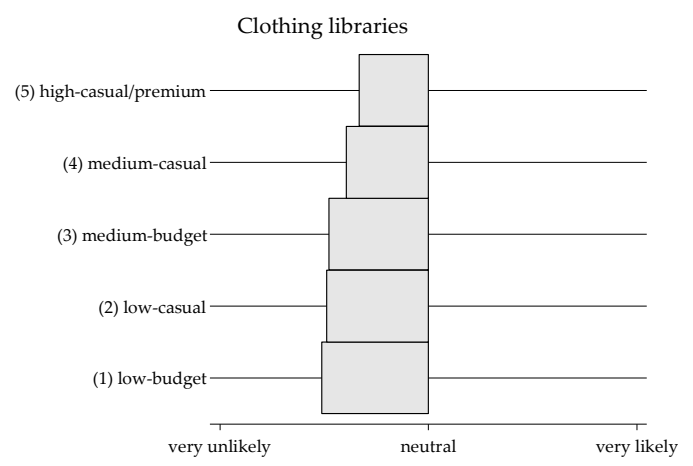

(a)

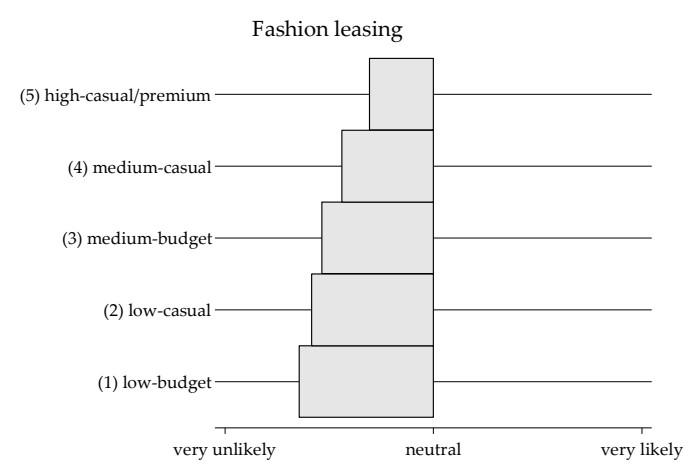

(c)

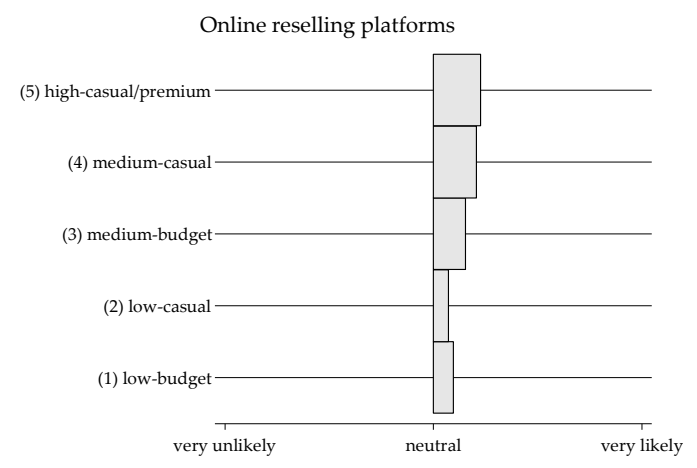

(e)

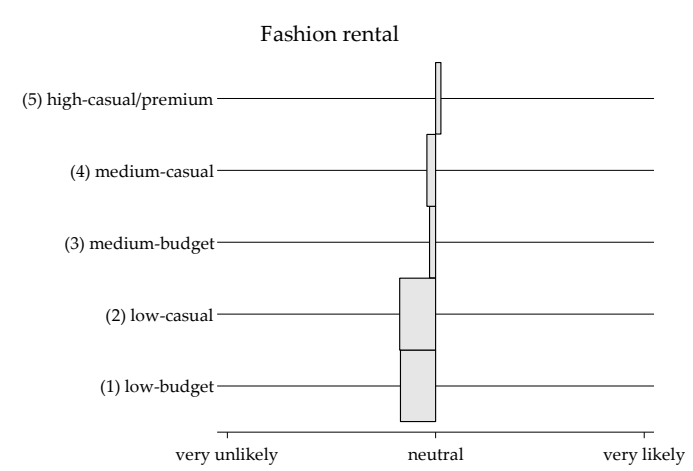

(b)

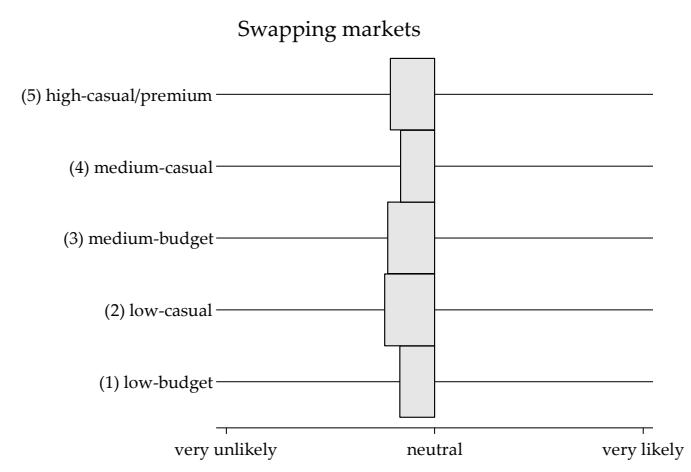

(d)

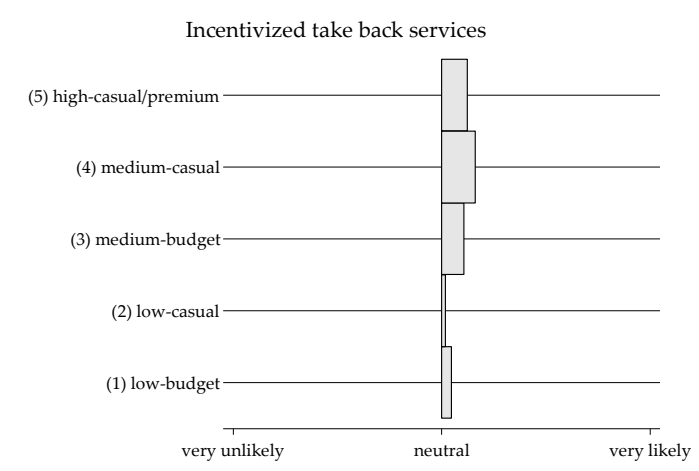

$(\mathbf{f})$

Figure 6. Cont. 


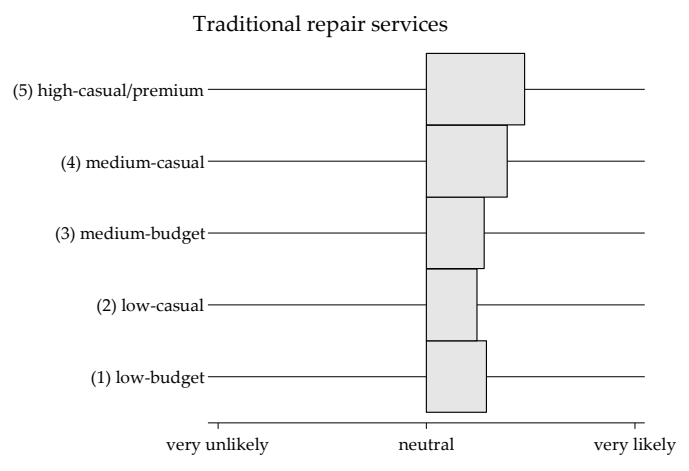

(g)

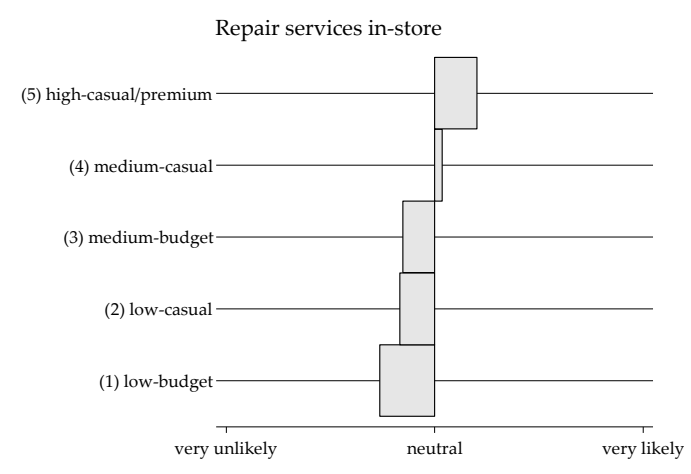

(h)

Figure 6. Future use intention of alternative business models by consumer segment. Please add the title for (a) clothing libraries, (b) fashion rental, (c) fashion leasing, (d) swapping markets, (e) online reselling platforms, (f) incentivized take back services, (g) traditional repair services, (h) repair services in-store.

\section{Discussion}

Successfully reducing the environmental impact of clothing consumption will require the design and implementation-for all three consumption phases-of behavioral strategies tailored to the characteristics and preferences of different consumer groups. This current paper contributes to the understanding of such strategies by descriptively analyzing different clothing consumer groups based not on traditional segmentation variables such as demographics but on actual purchasing behavior. This approach better encapsulates consumer heterogeneity while more fully identifying clothing consumption patterns. Such identification is highly relevant to developing strategies that foster environmentally friendly clothing consumption because it allows consideration of suitable strategies in relation to the actual purchasing patterns of specific consumer groups. In the following section, therefore, we propose such strategies for the different consumption phases and discuss their applicability to each consumer segment.

\subsection{Purchase Phase}

For the purchase phase, we propose two main strategies for reducing environmental impact: (1) consuming differently (e.g., purchasing recycled or second-hand products or clothing made of environmentally friendly materials like organic cotton); and (2) consuming less [20]. These strategies are applicable to each of our five consumer groups in the following ways:

Segment 1 (low consumption - budget brands). This largest consumer segment, which possesses the lowest number of $t$-shirts and jeans bought primarily from budget brands or second-hand outlets, also has the lowest income and is the least open to alternative business models. Although these consumers' relatively low number of clothing purchases may seem environmentally promising and in line with the most environmentally significant purchasing strategy of lowering overall consumption [1], this already low consumption may mean that reduction is not the optimal approach to improving this segment's environmental impact. At the same time, the group's consumption of relatively cheap budget brands, although possibly a reflection of a lack of interest in clothing other than for functional necessity, may be related to their low income. Whichever the case, their budget considerations indicate an unwillingness to pay any additional costs to shift from conventional clothing products to more environmentally friendly alternatives. Hence, although consuming differently could be a more promising avenue for this segment, the question remains of how this strategy would be realized. Not only might budget constraints or lack of interest prevent a shift toward more environmentally friendly and potentially more expensive clothing, but, according to our findings, environmentally friendly materials receive little consumer support. In particular, our respondents' reported willingness to pay for more environmentally friendly materials (e.g., recycled or second-hand) is far lower than 
their willingness to pay for conventional material. It may thus prove difficult to target this major consumer segment for the promotion of behavioral change. Rather, this segment's environmental impact may be more successfully lowered if the strategies of consuming less and consuming differently are successfully combined. For example, reducing consumption by a few clothing items (e.g., a "1-item less" campaign) could potentially free up monetary resources for investment in more environmentally friendly products. Another possible avenue would be to redirect their preferences toward alternative business models by leveraging their existing use of classic alternative acquisition (e.g., second-hand) to counter their comparably low acceptance of novel but low-cost alternatives (e.g., clothing libraries or swap markets). Strengthening second-hand consumption via image campaigns or new online shops to improve user experiences with such clothing acquisition could foster behaviors that meet the segment's needs but are more environmentally friendly. In general, future interventions targeting these consumers should specifically delineate how they could change their behavior in an environmentally friendly direction without undertaking additional costs.

Segment 2 (low consumption-casual/medium). Although Segment 2 consumption is similar to that of Segment 1 in number of items bought in a three-month period, these consumers enjoy a higher income, spend significantly more, and buy more casual/medium priced brands. This segment can thus be more easily targeted with strategies that foster the purchase of clothing made from more environmentally friendly, albeit more expensive, material.

Segment 3 (medium consumption-budget). This group epitomizes the fast fashion consumer, having a comparatively high consumption rate but a strong preference for budget brands, which in this study, include purchases from supermarkets or other cheap vendors not necessarily seen as fast fashion retailers. Segment 3 is of particular relevance to this research, not only because of its general interest in clothing but also because of its expected high impact on the environment. More specifically, consumers who purchase 8.4 relatively inexpensive items during a three-month period for a total of 33 items per year might be a more promising target group for clothing consumption reduction strategies than the previous two groups. With regard to buying differently, these consumers' unwillingness to pay for alternative materials again implies a reluctance to spend more money on higher quality, more environmentally friendly clothing. Given current marketing tools, however, promoting a consuming less strategy would be even more challenging than compensating one product with another (consuming differently), especially given that the question of how much is enough remains controversial. One behavioral change solution offered by social marketing is the "use of marketing principles and techniques to influence a target audience to voluntarily accept, reject, modify, or abandon a behavior for the benefit of individuals, groups, or society as a whole" ([37], p. 394). Hence, one possible social marketing tool for encouraging consumption would be to adopt a consumer viewpoint rather than making consumers feel guilty [37]. From this perspective, understanding the underlying motivation for Segment 3's consumption patterns would assist in the development of effective behavioral interventions. Alternatively, future interventions might emphasize alternative means of clothes acquisition that have an assumed lower environmental impact (e.g., fashion leasing or rental) without restricting the number of items acquired [48]. At present, however, this segment shows little support for either of these alternatives, which would thus need to be promoted.

Segments 4 (medium consumption-casual/medium) and 5 (high consumption-casual/medium and premium). Although Segments 4 and 5 together comprise the smallest group of consumers, both groups are very interesting in terms of composition and reported behavior. Most notably, both reported the highest clothing purchasing rates, indicating that each spends significantly more on clothing than the other three segments. Nonetheless, Segment 5 differs from Segment 4 in spending distinctly more and buying more premium brands. Interestingly, however, both segments reported purchasing clothing in the most environmentally friendly manner. Given the two groups' behavior patterns and monetary resources, both consuming less and consuming differently could be relevant strategies for these groups. That is, even though the large quantity purchased is the direct opposite of environmental friendliness, both segments exhibit environmental traits such as assigning the highest monetary value to jeans made 
of recycled and second-hand material and engaging in more consumption of environmental apparel. Even if this latter is due to an increased interest in clothing in general, it could be a promising starting point for introducing the strategies for more environmentally friendly clothing consumption to both segments. Respondents from these groups also reported the highest use of and support for alternative business models like fashion libraries and fashion rental. These tendencies are also promising for pushing Segments 4 and 5 toward more environmentally friendly consumption alternatives without necessarily compromising the quantity purchased. At the same time, raising both segments' awareness about consuming less remains of utmost importance because reducing consumption in these groups would result in a more substantial lowering of environmental impact per consumer than in any other segment. Nonetheless, because promoting behavior change is a balancing act between identifying the meaningful behavior to be changed and the meaningful target group, any strategy needs to take into account that Segments 4 and 5 are very small (6.8\% and $2.5 \%$, respectively), which might reduce the penetration of any behavioral intervention.

\subsection{Use and Maintenance Phase}

In this second phase, the target group (consumer segment, in our case) matters little because rather than identifying notable differences, our analysis highlights mostly similarities. The most noteworthy of these are the time that $t$-shirts and jeans are kept, the frequency of wearing, and laundry behaviors. Nevertheless, this consumption phase warrants some discussion because of life cycle assessment experts' disagreement over whether it has a significant [33,49] or negligible [1] impact on the environment. Given that a longer product life is generally preferable to a shorter one, retaining jeans and $t$-shirts for 3-4 years is a more positive outcome than the 2.2 years reported by Gracey and Moon [35]. In fact, all five of our consumer segments indicate the same period, which is particularly surprising given that Segments 1 and 3 purchase primarily budget brands while Segment 5 purchases casual/medium and premium brands. This finding not only contradicts the common environmental literature assumption (e.g., [50]) that premium brand clothing (assumedly of higher quality and durability) is kept longer but also implies that any recommendation to purchase higher quality clothing for environmental reasons will be ineffective if consumers do not simultaneously reduce their overall consumption or use the items for a longer period. In addition, although we are unable to distinguish whether the indicated 3-4 years reflects the active wearing of clothes or includes passive storage, we do know that the 36 to 48 times that both t-shirts and jeans are generally worn over their product lives exceeds the anticipated 22 times for $\mathrm{t}$-shirts but falls drastically short of the anticipated 200 times for jeans [1,33]. Based on a maximum four-year lifetime for jeans and t-shirts, the number of wears, and the number of wears before washing, we estimate a total of 22 washing cycles for a t-shirt and around six washing cycles for a pair of jeans at an average temperature of $40^{\circ} \mathrm{C}$. Whereas washing $1 \mathrm{~kg}$ clothes at $40^{\circ} \mathrm{C}$ consumes $0.21 \mathrm{kWh}$ of energy, tumble drying it requires 3-4 times as much energy [1], making it the most interesting maintenance practice from an environmental perspective $[33,51]$. In our study, in line with earlier research [1], around $30 \%$ of consumers use a tumble dryer to dry their $\mathrm{t}$-shirts and jeans. (It is worth noting that the use of tumble dryers is much higher in the U.S. (above 80\%) compared to the European countries (between ca. 12\% in Poland and ca. $20 \%$ in Germany and Sweden)) Although the environmental impact of this practice is rather low compared to impacts in the production, purchase, and discard phases [1], for future interventions targeting the use phase, the behavior with the highest potential to reduce impact across all consumer segments is the widespread use of energy gobbling tumble dryers.

\subsection{Discard Phase}

Lastly, the results related to general clothing disposal practices suggest that consumers widely use environmentally friendly means of discarding their unwanted items, with only $14.1 \%$ going into the trash. It should be noted, however, that this finding stands in strong contrast to the 2014 U.S. Environmental Protection Agency statistic of $64.5 \%$ of textiles and clothing going into a landfill [34]. 
Even though this figure is country specific and includes textiles as well as clothing, the difference seems profound. Hence, environmental impact reducing strategies for the disposal phase should focus on the reintroduction of unwanted clothing into the production cycle by facilitating consumer recycling of clothing items to give them a second product life. Achieving this circular flow of materials through in-store take back and other product care services beyond the moment of purchase would benefit the environment by reducing not only waste generation but also the use of virgin materials.

\section{Conclusions}

Clothing consumption's high environmental impact raises concerns at each phase of a clothing item's life cycle, the severity of which is determined largely by which and how many clothing items consumers purchase and how often, as well as the frequency of item use and the nature of their maintenance and disposal. However, although developing tailored strategies that successfully address consumer decisions across all phases of clothes consumption is a key element in achieving more sustainable clothing consumption, previous research has only fragmentally examined how consumers behave in relation to each phase. This current analysis has thus examined the consumer clothing behavior of large, diverse consumer samples in four Western countries to provide a comprehensive and up-to-date assessment of consumer clothing consumption across four important clothing markets. In doing so, it supplemented the extensive data on self-reported consumer behavior with the environmental concerns generated by each clothing life cycle phase. To address consumer heterogeneity, it divided consumers into five distinct segments based on extent of consumption and price point of product purchased. This segmentation enabled a better understanding of clothing consumption and the development of change interventions for targeting specific behaviors. Basing the segmentation on actual consumption produced five consumer groups offering important insights into both distinctions and similarities in consumer purchasing, use and maintenance, and disposal behavior.

Among the most notable findings are the relatively low clothing consumption-rate by almost half the respondents and their strong preference for budget brand clothing. For the low clothing consumers in Segment 1, shifting behavior toward low cost acquisition alternatives is likely to be a more effective approach than trying to further reduce consumption, whereas both approaches-consuming differently and consuming less-are promising for the high volume and high spending consumers in Segments 4 and 5. Segment 2 consumers, on the other hand, who engage in low consumption but higher spending, could be addressed by strategies that promote consuming differently, whereas strategies to raise awareness of the need to consume less could best serve the high volume, budget brand consumers in Segment 3. The design and implementation of any strategy, however, should take into account that no one message can suit all consumer groups; to be successful, interventions must be adapted to each segments' consumption patterns. The pattern identification and consumer profiling reported here constitutes a first step in this direction, one that provides an important platform for future research aimed at even more comprehensive understanding of clothing consumption. Nonetheless, because simply identifying different behaviors is insufficient to engendering actual behavior change, more research is needed to understand such in-depth aspects as the motivations underlying these actions.

This study is of course not without its limitations, not least the potential for a social desirability or method bias to which all studies of self-reported behavior are subject (see e.g., [52]). A social desirability bias would lead to an over- or underestimation of behavior for all categories, while consumer inability to accurately recall actions in the given time period on a general abstract level would produce different accountings of behavior. The latter is particularly relevant for respondent recall of such past behavior as how many items they purchased in the previous three months, the amount of money spent, and the number of $t$-shirts and jeans they currently own. In this context, cross-validations of measurements such as surveys and observation experiments or real-time data collection could be a promising way to increase validity and reliability. Another limitation is the cross-sectionality of the study, which may not sufficiently capture the great variation in consumer behavior, especially in such a fast-moving context as the fashion industry. When the study aim is to better understand consumer behavior to 
enable the design of effective behavioral change interventions, assessing consumption pattern stability and tracing its development is crucial. Finally, although Western countries have some of the largest clothing markets, studying them to the exclusion of highly populated, growing economies such as Brazil, China, and India ignores purchasing, maintenance, and disposal behaviors that may diverge greatly from the Western behavior patterns reported here. Hence, extending the current analysis to developing nations would be an important avenue for future research.

Despite these shortcomings, the present study contributes important and extensive empirical knowledge that can prompt rethinking of previous assumptions about such aspects as clothes purchasing behavior or the relation between age and clothing consumption. Surprisingly, however, we identify no significant age-based differences between our five segments. In fact, the similar age distribution in our medium-budget Segment 3 refutes the commonly accepted notion of the young fast fashion consumer. Although one reason may be that very young consumers (under 18) are not included in the sample, Segment 3's budget purchases are not necessarily made at traditional fast fashion retailers but may take place at nontraditional clothes vendors such as supermarkets. Hence, although the current data provide many interesting insights, they also raise at least as many questions for future investigation. One potential research avenue would be to further explore the segments' demographics or make more detailed comparisons of the different countries. Another important "next step" would be to supplement the findings reported here with psychological insights to provide clearer explanation of the segmental behavior differences based on their psychological underpinnings and to identify which behavioral antecedents could be targeted most effectively in future interventions. Likewise, an assessment of the actual environmental impact of the various consumer segments could support the development of effective behavioral interventions promoting truly environmentally friendly clothing consumption.

Acknowledgments: We gratefully acknowledge the Trash-2Cash project (grant agreement No. 646226) funded by the European Community under Horizon2020 research and innovation program and the Mistra Future Fashion Project Phase II funded by the Swedish Mistra Foundation. This grant does not cover the publication cost for open access. However, the funding source does not hold any competing interest.

Author Contributions: Kristian Steensen Nielsen, Tina Müller and Wencke Gwozdz designed the study and wrote the paper. Wencke Gwozdz carried out the data analyses. All authors provided feedback throughout the research process and proofread the paper.

Conflicts of Interest: The authors declare no conflict of interest. 


\section{Appendix A}

Table A1. Descriptive statistics for acquisition mode and sociodemographics.

\begin{tabular}{|c|c|c|c|c|c|c|c|c|c|c|c|c|}
\hline & \multicolumn{2}{|c|}{ All } & \multicolumn{2}{|c|}{$\begin{array}{c}\text { Segment } 1 \\
\text { Low-Budget }\end{array}$} & \multicolumn{2}{|c|}{$\begin{array}{c}\text { Segment } 2 \\
\text { Low-Casual }\end{array}$} & \multicolumn{2}{|c|}{$\begin{array}{c}\text { Segment } 3 \\
\text { Medium-Budget }\end{array}$} & \multicolumn{2}{|c|}{$\begin{array}{c}\text { Segment } 4 \\
\text { Medium-Casual }\end{array}$} & \multicolumn{2}{|c|}{$\begin{array}{c}\text { Segment } 5 \\
\text { High-Premium }\end{array}$} \\
\hline & Mean & (SD) & Mean & (SD) & Mean & (SD) & Mean & (SD) & Mean & (SD) & Mean & (SD) \\
\hline \multicolumn{13}{|l|}{ Socio-demographics } \\
\hline Germany (dummy) & 0.26 & $(0.44)$ & 0.20 & $(0.40)$ & 0.28 & $(0.45)$ & 0.34 & $(0.47)$ & 0.33 & $(0.47)$ & 0.40 & $(0.49)$ \\
\hline Poland (dummy) & 0.24 & $(0.43)$ & 0.35 & $(0.48)$ & 0.18 & $(0.38)$ & 0.14 & $(0.35)$ & 0.13 & $(0.34)$ & 0.04 & $(0.20)$ \\
\hline Sweden (dummy) & 0.25 & $(0.43)$ & 0.25 & $(0.43)$ & 0.22 & $(0.41)$ & 0.31 & $(0.46)$ & 0.28 & $(0.45)$ & 0.19 & $(0.39)$ \\
\hline U.S. (dummy) & 0.25 & $(0.43)$ & 0.20 & $(0.40)$ & 0.33 & $(0.47)$ & 0.21 & $(0.41)$ & 0.26 & $(0.44)$ & 0.37 & (0.49) \\
\hline Age (years) & 42.59 & $(13.54)$ & 42.35 & $(14.20)$ & 43.55 & $(13.53)$ & 42.06 & $(12.78)$ & 42.54 & $(12.20)$ & 41.05 & $(11.39)$ \\
\hline Male (dummy) & 0.44 & $(0.50)$ & 0.36 & $(0.48)$ & 0.52 & $(0.50)$ & 0.45 & $(0.50)$ & 0.48 & $(0.50)$ & 0.57 & $(0.50)$ \\
\hline Income (11 categories) & 4.69 & (3.15) & 3.83 & $(2.82)$ & 4.78 & (3.17) & 5.28 & (3.12) & 6.76 & (3.01) & 8.00 & $(2.92)$ \\
\hline
\end{tabular}

Table A2. Descriptive statistics for the use and maintenance phase.

\begin{tabular}{|c|c|c|c|c|c|c|c|c|c|c|c|c|c|}
\hline & & \multicolumn{2}{|c|}{ All } & \multicolumn{2}{|c|}{$\begin{array}{c}\text { Segment } 1 \\
\text { Low-Budget }\end{array}$} & \multicolumn{2}{|c|}{$\begin{array}{c}\text { Segment } 2 \\
\text { Low-Casual }\end{array}$} & \multicolumn{2}{|c|}{$\begin{array}{c}\text { Segment } 3 \\
\text { Medium-Budget }\end{array}$} & \multicolumn{2}{|c|}{$\begin{array}{c}\text { Segment } 4 \\
\text { Medium-Casual }\end{array}$} & \multicolumn{2}{|c|}{$\begin{array}{c}\text { Segment } 5 \\
\text { High-Premium }\end{array}$} \\
\hline & & Mean & (SD) & Mean & (SD) & Mean & (SD) & Mean & (SD) & Mean & (SD) & Mean & (SD) \\
\hline \multicolumn{14}{|l|}{ Use } \\
\hline \multirow{2}{*}{ Items possessing (number) } & jeans & 6.00 & $(4.90)$ & 5.08 & $(4.25)$ & 5.86 & $(4.40)$ & 6.62 & $(4.93)$ & 8.51 & (6.36) & 11.16 & (8.29) \\
\hline & t-shirts & 18.56 & (12.72) & 17.02 & $(11.85)$ & 18.46 & $(12.24)$ & 19.75 & $(13.02)$ & 22.90 & $(15.38)$ & 24.37 & $(16.15)$ \\
\hline \multirow{2}{*}{ Time keeping ${ }^{1}$} & jeans & 4.10 & $(0.95)$ & 4.19 & $(0.90)$ & 4.18 & $(0.92)$ & 3.96 & $(0.98)$ & 3.83 & $(1.05)$ & 3.52 & $(1.13)$ \\
\hline & t-shirts & 3.93 & (1.03) & 4.05 & $(0.96)$ & 4.01 & $(1.03)$ & 3.78 & $(1.00)$ & 3.47 & $(1.22)$ & 3.35 & $(1.18)$ \\
\hline \multirow{2}{*}{ Wears on average ${ }^{2}$} & jeans & 4.30 & $(1.08)$ & 4.31 & (1.14) & 4.34 & (1.01) & 4.28 & (1.04) & 4.17 & $(1.04)$ & 4.25 & $(0.91)$ \\
\hline & t-shirts & 4.35 & $(0.91)$ & 4.42 & $(0.89)$ & 4.36 & $(0.90)$ & 4.30 & $(0.91)$ & 4.13 & $(1.04)$ & 4.24 & $(0.99)$ \\
\hline \multirow{2}{*}{ Wears before washing (number) } & jeans & 8.24 & $(9.70)$ & 8.66 & (10.16) & 8.06 & $(9.65)$ & 8.14 & (9.52) & 7.34 & (8.11) & 6.39 & (7.01) \\
\hline & t-shirts & 2.26 & $(1.87)$ & 2.45 & $(2.03)$ & 2.20 & $(1.79)$ & 2.05 & $(1.69)$ & 1.98 & $(1.58)$ & 1.92 & $(1.87)$ \\
\hline \multicolumn{14}{|l|}{ Maintenance } \\
\hline \multirow{2}{*}{ Washing temperature $\left({ }^{\circ} \mathrm{Celsius}\right)$} & jeans & 38.81 & $(10.00)$ & 39.57 & $(9.82)$ & 38.12 & (10.61) & 38.45 & (9.39) & 38.11 & $(9.82)$ & 37.80 & (10.97) \\
\hline & t-shirts & 38.06 & $(9.74)$ & 39.01 & (9.63) & 37.47 & $(10.32)$ & 37.45 & (8.92) & 36.74 & $(9.47)$ & 36.60 & $(10.94)$ \\
\hline \multirow{2}{*}{ Detergent: none (dummy) } & jeans & 0.03 & $(0.18)$ & 0.04 & $(0.18)$ & 0.03 & $(0.18)$ & 0.03 & $(0.17)$ & 0.03 & $(0.16)$ & 0.04 & $(0.20)$ \\
\hline & t-shirts & 0.03 & $(0.17)$ & 0.03 & $(0.17)$ & 0.03 & $(0.17)$ & 0.03 & $(0.17)$ & 0.04 & $(0.20)$ & 0.04 & $(0.20)$ \\
\hline
\end{tabular}


Table A2. Cont.

\begin{tabular}{|c|c|c|c|c|c|c|c|c|c|c|c|c|c|}
\hline & & \multicolumn{2}{|c|}{ All } & \multicolumn{2}{|c|}{$\begin{array}{c}\text { Segment } 1 \\
\text { Low-Budget }\end{array}$} & \multicolumn{2}{|c|}{$\begin{array}{c}\text { Segment } 2 \\
\text { Low-Casual }\end{array}$} & \multicolumn{2}{|c|}{$\begin{array}{c}\text { Segment } 3 \\
\text { Medium-Budget }\end{array}$} & \multicolumn{2}{|c|}{$\begin{array}{c}\text { Segment } 4 \\
\text { Medium-Casual }\end{array}$} & \multicolumn{2}{|c|}{$\begin{array}{c}\text { Segment } 5 \\
\text { High-Premium }\end{array}$} \\
\hline & & Mean & (SD) & Mean & (SD) & Mean & (SD) & Mean & (SD) & Mean & (SD) & Mean & (SD) \\
\hline \multirow{2}{*}{ Detergent: non-eco (dummy) } & jeans & 0.65 & $(0.48)$ & 0.73 & $(0.44)$ & 0.59 & (0.49) & 0.62 & $(0.49)$ & 0.56 & $(0.50)$ & 0.57 & $(0.50)$ \\
\hline & t-shirts & 0.65 & $(0.48)$ & 0.73 & $(0.45)$ & 0.60 & $(0.49)$ & 0.62 & $(0.49)$ & 0.56 & $(0.50)$ & 0.58 & $(0.50)$ \\
\hline \multirow{2}{*}{ Detergent: eco (dummy) } & jeans & 0.31 & $(0.46)$ & 0.23 & $(0.42)$ & 0.37 & $(0.48)$ & 0.35 & $(0.48)$ & 0.42 & $(0.49)$ & 0.39 & $(0.49)$ \\
\hline & t-shirts & 0.31 & $(0.46)$ & 0.24 & $(0.43)$ & 0.37 & $(0.48)$ & 0.35 & $(0.48)$ & 0.40 & $(0.49)$ & 0.38 & $(0.49)$ \\
\hline \multirow{2}{*}{ Softener: none (dummy) } & jeans & 0.49 & $(0.50)$ & 0.48 & $(0.50)$ & 0.52 & $(0.50)$ & 0.51 & $(0.50)$ & 0.44 & $(0.50)$ & 0.49 & $(0.50)$ \\
\hline & t-shirts & 0.43 & $(0.50)$ & 0.42 & $(0.49)$ & 0.46 & $(0.50)$ & 0.43 & $(0.50)$ & 0.36 & $(0.48)$ & 0.45 & $(0.50)$ \\
\hline \multirow{2}{*}{ Softener: non-eco (dummy) } & jeans & 0.38 & $(0.49)$ & 0.43 & $(0.49)$ & 0.33 & $(0.47)$ & 0.36 & $(0.48)$ & 0.36 & $(0.48)$ & 0.33 & $(0.47)$ \\
\hline & t-shirts & 0.42 & $(0.49)$ & 0.47 & $(0.50)$ & 0.37 & $(0.48)$ & 0.41 & $(0.49)$ & 0.39 & $(0.49)$ & 0.31 & $(0.46)$ \\
\hline \multirow{2}{*}{ Softener: eco (dummy) } & jeans & 0.13 & $(0.33)$ & 0.09 & $(0.29)$ & 0.15 & $(0.36)$ & 0.13 & $(0.34)$ & 0.20 & $(0.40)$ & 0.18 & $(0.39)$ \\
\hline & t-shirts & 0.15 & $(0.36)$ & 0.11 & $(0.31)$ & 0.17 & $(0.38)$ & 0.15 & $(0.36)$ & 0.26 & $(0.44)$ & 0.24 & $(0.43)$ \\
\hline \multirow{2}{*}{ Dryer use (dummy) } & jeans & 0.32 & $(0.47)$ & 0.29 & $(0.46)$ & 0.36 & $(0.48)$ & 0.31 & $(0.46)$ & 0.36 & $(0.48)$ & 0.38 & $(0.49)$ \\
\hline & t-shirts & 0.34 & $(0.47)$ & 0.31 & $(0.46)$ & 0.39 & $(0.49)$ & 0.33 & $(0.47)$ & 0.34 & $(0.48)$ & 0.36 & $(0.48)$ \\
\hline
\end{tabular}

${ }^{1}$ Time keeping is measured in 5 categories: 1 "less than 6 months", 2 "less than a year", 3 "1-2 years", 4 " $3-4$ years", 5 " 5 years or more"; ${ }^{2}$ Wears on average is measured in five categories: 1 "once a year or less", 2 "less than once every 3 months", 3 "at least once every other month", 4 "at least once a month", and 5 "at least once a week".

Table A3. Descriptive statistics for the discarding phase.

\begin{tabular}{|c|c|c|c|c|c|c|c|c|c|c|c|c|c|}
\hline & & \multicolumn{2}{|c|}{ All } & \multicolumn{2}{|c|}{$\begin{array}{c}\text { Segment } 1 \\
\text { Low-Budget }\end{array}$} & \multicolumn{2}{|c|}{$\begin{array}{c}\text { Segment } 2 \\
\text { Low-Casual }\end{array}$} & \multicolumn{2}{|c|}{$\begin{array}{c}\text { Segment } 3 \\
\text { Medium-Budget }\end{array}$} & \multicolumn{2}{|c|}{$\begin{array}{c}\text { Segment } 4 \\
\text { Medium-Casual }\end{array}$} & \multicolumn{2}{|c|}{$\begin{array}{c}\text { Segment } 5 \\
\text { High-Premium }\end{array}$} \\
\hline & & Mean & (SD) & Mean & (SD) & Mean & (SD) & Mean & (SD) & Mean & (SD) & Mean & (SD) \\
\hline \multicolumn{14}{|l|}{ Discarding ${ }^{1}$} \\
\hline \multirow{3}{*}{ Second life (\%) } & general & 70.74 & $(29.97)$ & 69.03 & (31.86) & 70.94 & $(28.98)$ & 73.59 & $(27.97)$ & 72.42 & (27.38) & 69.85 & $(28.07)$ \\
\hline & jeans & 63.73 & (39.52) & 60.56 & $(41.60)$ & 63.58 & (38.70) & 67.83 & (37.58) & 68.95 & (35.28) & 71.79 & (32.44) \\
\hline & t-shirts & 52.15 & (39.26) & 49.72 & (39.94) & 51.34 & (39.17) & 55.80 & (38.47) & 56.34 & (37.09) & 60.81 & (36.76) \\
\hline \multirow{3}{*}{ Down-cycling (\%) } & general & 15.21 & (20.27) & 16.24 & (22.04) & 15.74 & $(20.21)$ & 12.62 & (17.28) & 14.30 & (17.06) & 15.92 & (18.41) \\
\hline & jeans & 14.57 & (26.35) & 15.64 & (28.76) & 15.46 & (26.36) & 11.83 & (22.81) & 13.18 & (21.87) & 12.98 & (19.10) \\
\hline & t-shirts & 27.76 & (33.36) & 29.89 & (35.27) & 28.19 & (33.03) & 24.03 & (30.57) & 25.25 & (30.53) & 24.29 & (29.46) \\
\hline \multirow{3}{*}{ Trash (\%) } & general & 14.05 & (23.30) & 14.73 & $(24.92)$ & 13.32 & (22.02) & 13.81 & (22.56) & 13.28 & (20.78) & 14.23 & $(20.27)$ \\
\hline & jeans & 21.71 & (33.97) & 23.83 & (36.08) & 20.97 & (32.90) & 20.33 & (32.65) & 17.87 & (29.72) & 15.23 & (26.44) \\
\hline & $\mathrm{t}$-shirts & 20.12 & (31.73) & 20.44 & (32.68) & 20.47 & (31.53) & 20.17 & (31.13) & 18.41 & (30.25) & 14.90 & (25.58) \\
\hline
\end{tabular}

${ }^{1}$ Second life, down-cycling and trash together sum up to $100 \%$ (within one category). 
Table A4. Descriptive statistics for environmentally friendly clothing consumption behavior.

\begin{tabular}{|c|c|c|c|c|c|c|c|c|c|c|c|c|}
\hline & \multicolumn{2}{|c|}{ All } & \multicolumn{2}{|c|}{$\begin{array}{l}\text { Segment } 1 \\
\text { Low-Budget }\end{array}$} & \multicolumn{2}{|c|}{$\begin{array}{c}\text { Segment } 2 \\
\text { Low-Casual }\end{array}$} & \multicolumn{2}{|c|}{$\begin{array}{c}\text { Segment } 3 \\
\text { Medium-Budget }\end{array}$} & \multicolumn{2}{|c|}{$\begin{array}{c}\text { Segment } 4 \\
\text { Medium-Casual }\end{array}$} & \multicolumn{2}{|c|}{$\begin{array}{c}\text { Segment } 5 \\
\text { High-Premium }\end{array}$} \\
\hline & Mean & (SD) & Mean & (SD) & Mean & (SD) & Mean & (SD) & Mean & (SD) & Mean & (SD) \\
\hline \multicolumn{13}{|c|}{ Environmental apparel consumption ${ }^{1}$} \\
\hline EAC (mean score) & 2.68 & $(0.80)$ & 2.61 & $(0.76)$ & 2.70 & $(0.83)$ & 2.70 & $(0.76)$ & 2.89 & $(0.87)$ & 2.98 & $(0.90)$ \\
\hline \multicolumn{13}{|l|}{ Value of material ${ }^{2}$} \\
\hline \multirow{2}{*}{ Recycled } & 64.81 & (42.47) & 63.13 & $(40.40)$ & 63.58 & $(43.16)$ & 66.45 & $(42.81)$ & 72.32 & $(47.52)$ & 72.71 & (49.13) \\
\hline & 62.01 & $(43.79)$ & 60.21 & (41.53) & 61.39 & $(44.12)$ & 64.26 & $(45.33)$ & 66.67 & (47.41) & 68.39 & $(52.63)$ \\
\hline \multirow{2}{*}{ Second-hand } & 40.85 & $(37.10)$ & 40.71 & (36.50) & 41.34 & $(36.88)$ & 39.09 & (35.39) & 42.61 & $(43.35)$ & 47.98 & $(44.47)$ \\
\hline & 36.49 & (39.12) & 35.42 & $(37.48)$ & 37.97 & $(40.06)$ & 34.90 & $(37.26)$ & 39.11 & $(46.62)$ & 45.26 & $(47.64)$ \\
\hline \multirow{2}{*}{ New organic } & 97.51 & $(43.26)$ & 92.48 & $(42.42)$ & 97.57 & $(44.37)$ & 102.90 & $(42.38)$ & 107.65 & $(40.01)$ & 111.03 & $(48.34)$ \\
\hline & 96.27 & $(44.18)$ & 91.19 & $(43.11)$ & 96.02 & $(45.51)$ & 102.31 & $(42.88)$ & 105.02 & $(42.72)$ & 112.39 & $(49.03)$ \\
\hline \multicolumn{13}{|c|}{ Alternative business models: past use ${ }^{3}$} \\
\hline Clothing libraries & 0.05 & $(0.21)$ & 0.03 & $(0.18)$ & 0.04 & $(0.20)$ & 0.05 & $(0.22)$ & 0.10 & $(0.30)$ & 0.17 & $(0.38)$ \\
\hline Fashion rental & 0.17 & $(0.38)$ & 0.15 & $(0.36)$ & 0.15 & $(0.36)$ & 0.20 & $(0.40)$ & 0.25 & $(0.43)$ & 0.33 & $(0.47)$ \\
\hline Fashion leasing & 0.04 & $(0.19)$ & 0.02 & $(0.13)$ & 0.03 & $(0.18)$ & 0.04 & $(0.20)$ & 0.09 & $(0.28)$ & 0.22 & $(0.42)$ \\
\hline Swapping markets & 0.16 & $(0.37)$ & 0.17 & $(0.37)$ & 0.15 & $(0.35)$ & 0.16 & $(0.37)$ & 0.19 & $(0.40)$ & 0.26 & $(0.44)$ \\
\hline Reselling clothes online & 0.41 & $(0.49)$ & 0.39 & $(0.49)$ & 0.38 & $(0.49)$ & 0.45 & $(0.50)$ & 0.51 & $(0.50)$ & 0.49 & $(0.50)$ \\
\hline Incentivized take back services & 0.14 & $(0.35)$ & 0.11 & $(0.31)$ & 0.15 & $(0.35)$ & 0.17 & $(0.38)$ & 0.22 & $(0.41)$ & 0.24 & $(0.43)$ \\
\hline Traditional repair service & 0.65 & $(0.48)$ & 0.66 & $(0.47)$ & 0.62 & $(0.49)$ & 0.64 & $(0.48)$ & 0.69 & $(0.46)$ & 0.78 & $(0.42)$ \\
\hline In-store repair service & 0.12 & $(0.32)$ & 0.08 & $(0.28)$ & 0.12 & $(0.33)$ & 0.12 & $(0.32)$ & 0.23 & $(0.42)$ & 0.30 & $(0.46)$ \\
\hline \multicolumn{13}{|c|}{ Alternative business models: future use intention ${ }^{4}$} \\
\hline Clothing libraries & 25.74 & $(29.21)$ & 24.47 & (29.08) & 25.62 & $(28.66)$ & 26.11 & (28.73) & 30.30 & (31.07) & 33.43 & $(33.84)$ \\
\hline Fashion rental & 43.63 & $(33.90)$ & 41.52 & $(34.10)$ & 41.38 & $(33.09)$ & 48.56 & $(33.36)$ & 47.93 & $(34.52)$ & 51.30 & $(35.81)$ \\
\hline Fashion leasing & 20.85 & (26.59) & 17.78 & (24.65) & 20.78 & $(26.27)$ & 23.20 & (27.15) & 28.04 & (30.35) & 34.70 & (35.23) \\
\hline Swapping markets & 40.03 & (34.41) & 41.65 & (35.43) & 38.00 & (33.02) & 38.79 & (33.45) & 41.82 & (35.47) & 39.40 & (35.33) \\
\hline Reselling clothes online & 55.66 & (35.73) & 54.87 & $(36.22)$ & 53.59 & $(35.04)$ & 57.72 & $(35.08)$ & 60.41 & $(35.91)$ & 61.40 & (37.34) \\
\hline Incentivized take back services & 53.14 & $(35.29)$ & 52.46 & $(36.22)$ & 51.01 & $(34.74)$ & 55.32 & (34.12) & 58.03 & (34.12) & 56.20 & (35.81) \\
\hline Traditional repair service & 64.28 & (33.67) & 64.45 & (34.47) & 62.15 & (33.65) & 63.83 & (33.05) & 69.48 & (30.89) & 73.70 & (29.43) \\
\hline In-store repair service & 40.89 & (33.53) & 36.82 & (33.05) & 41.66 & (33.32) & 42.36 & (33.08) & 51.82 & (33.82) & 60.10 & (32.64) \\
\hline
\end{tabular}

${ }^{1}$ EAC is a mean score of eight items measured on a five-point scale ranging from 1 "very rarely or never" to 5 "very often or always"; ${ }^{2}$ Value of material is measured by the question "If a pair of new conventional jeans is a $100 \%$, how much would you pay for exactly the same pair of ... "-answer scale is continuous and ranges from 0 to $200 ;{ }^{3}$ Past use of alternative business models is measured by a dummy 0 "no", 1 "yes"; 4 Future use intention of alternative business models is measured as: 0 "very unlikely", 50 "neutral", and 100 "very likely" on a continuous scale. 


\section{References}

1. Roos, S.; Sandin, G.; Zamani, B.; Peters, G.; Svanström, M. Will clothing be sustainable? Clarifying sustainable fashion. In Textiles and Clothing Sustainability; Muthu, S.S., Ed.; Springer: Singapore, 2017; pp. 1-45.

2. McAfee, A.; Dessain, V.; Sjoeman, A. Zara: IT for Fast Fashion; Harvard Business Review: Boston, MA, USA, 2004.

3. Foroohar, R.; Stabe, M. Fabulous fashion: Low-cost companies like Zara and Topshop are emerging as defining and dominant players, not just followers. Newsweek Int. 2005, 17, 30.

4. Kim, H.; Jung Choo, H.; Yoon, N. The motivational drivers of fast fashion avoidance. J. Fash. Mark. Manag. 2013, 17, 243-260. [CrossRef]

5. Niinimäki, K.; Hassi, L. Emerging design strategies in sustainable production and consumption of textiles and clothing. J. Clean. Prod. 2011, 19, 1876-1883. [CrossRef]

6. Choudhury, A.K.R. Environmental impacts of the textile industry and its assessment through life cycle assessment. In Roadmap to Sustainable Textiles and Clothing, Environmental and Social Aspects of Textiles and Clothing Supply Chain; Muthu, S.S., Ed.; Springer: Singapore, 2014; pp. 1-39.

7. Boström, M.; Micheletti, M. Introducing the sustainability challenge of textiles and clothing. J. Consum. Policy 2016, 39, 367-375. [CrossRef]

8. Deloitte-Christiansen, A.M.; Hvidsteen, K.; Haghshenas, B. Fashioning Sustainability 2013; Deloitte: Copenhagen, Denmark, 2013.

9. Moore, S.B.; Wentz, M. Eco-labeling for textiles and apparel. In Sustainable Textiles: Life Cycle and Environmental Impact; Blackburn, R.S., Ed.; Woodhead Publishing: Cambridge, UK, 2009; pp. 214-230.

10. Textile World. Water and Energy-Saving Solutions. Textile World Special Report. March/April 2008. Available online: http://www.textileworld.com/Issues/2008/March-April/Dyeing_Printing_and_ Finishing/Water-And_Energy-Saving_Solutions (accessed on 13 February 2017).

11. Pfister, S.; Koehler, A.; Hellweg, S. Assessing the environmental impacts of freshwater consumption in LCA. Environ. Sci. Technol. 2009, 43, 4098-4104. [CrossRef] [PubMed]

12. Ecotextiles, O. Why Do We Offer Safe Fabrics? Available online: https://oecotextiles.wordpress.com/ (accessed on 4 January 2017).

13. Greenpeace International. Dirty Laundry 2: Hung out to Dry. 2011. Available online: http://www. greenpeace.org/international/en/publications/reports/Dirty-Laundry-2/ (accessed on 13 February 2017).

14. Peters, G.M.; Granberg, H.; Sweet, S. The role of science and technology in sustainable fashion. In Routlegde Handbook of Sustainability and Fashion; Fletcher, K., Tham, M., Eds.; Taylor \& Francis: London, UK, 2014; pp. 181-190.

15. Roos, J.M. Konsumtionsrapporten 2010; The Consumer Report 2010; Center for Consumer Science, University of Gothenburg: Gothenburg, Sweden, 2010.

16. Roos, S.; Sandin, G.; Zamani, B.; Peters, G. Environmental Assessment of Swedish Fashion Consumption; Five Garments-Sustainable Futures; Mistra Future Fashion: Borås, Sweden, 2015.

17. American Apparel and Footwear Association. ApparelStats 2014. Arlington, VA, USA. Available online: www.wewear.org/apparelstats-2014-and-shoestats-2014-reports/ (accessed on 23 March 2017).

18. Connolly, J.; Prothero, A. Sustainable consumption: Consumption, consumers and the commodity discourse. Consum. Mark. Cult. 2003, 6, 275-291. [CrossRef]

19. Kozar, J.M.; Hiller Connell, K.Y. Socially and environmentally responsible apparel consumption: Knowledge, attitudes, and behaviors. Soc. Responsib. J. 2013, 9, 315-324. [CrossRef]

20. Roos, S.; Zamani, B.; Sandin, G.; Peters, G.M.; Svanström, M. A life cycle assessment (LCA)-based approach to guiding an industry sector towards sustainability: The case of the Swedish apparel sector. J. Clean. Prod. 2016, 133, 691-700. [CrossRef]

21. Textile Exchange. Organic Cotton Market Report 2016. Annual Report. 2016. Available online: http:/ / textileexchange.org/wp-content/uploads/2017/02/TE-Organic-Cotton-Market-ReportOct2016.pdf (accessed on 4 May 2017).

22. Ha-Brookshire, J.E.; Norum, P.S. Willingness to pay for socially responsible products: Case of cotton apparel. J. Consum. Mark. 2011, 28, 344-353. [CrossRef]

23. Ellis, J.L.; McCracken, V.A.; Skuza, N. Insights into willingness to pay for organic cotton apparel. J. Fash. Mark. Manag. Int. J. 2012, 16, 290-305. [CrossRef] 
24. Mont, O. Institutionalisation of sustainable consumption patterns based on shared use. Ecol. Econ. 2004, 50, 135-153. [CrossRef]

25. Stamminger, R. Consumer real life behaviour compared to standard in washing and dishwashing. In Proceedings of the WFK 44th International Detergency Conference, Düsseldorf, Germany, 12-14 May 2009; pp. 89-100.

26. Laitala, K.; Boks, C.; Klepp, I.G. Potential for environmental improvements in laundering. Int. J. Consum. Stud. 2011, 35, 254-264. [CrossRef]

27. Gwozdz, W.; Netter, S.; Bjartmarz, T.; Reisch, L.A. Survey Results on Fashion Consumption and Sustainability among Young Swedes; Report Mistra Future Fashion; Mistra Future Fashion: Borås, Sweden, 2013.

28. Van Hoof, G.; Schowanek, D.; Feijtel, T.C. Comparative life-cycle assessment of laundry detergent formulations in the UK. Part I: Environmental fingerprint of five detergent formulations in 2001. Tenside Surfactants Deterg. 2003, 40, 266-275.

29. Järvi, P.; Paloviita, A. Product-related information for sustainable use of laundry detergents in Finnish Households. J. Clean. Prod. 2007, 15, 681-689. [CrossRef]

30. Faberi, S. Domestic Washing Machines and Dishwashers. Preparatory studies for Eco-design requirements of EuP. 2007. Available online: https:/ / circabc.europa.eu/sd/a/5eedd0be-bc43-4506-81b2-2a825eb79e01/ Lot24_Dish_T4_ENER\%20clean_final.pdf (accessed on 6 May 2017).

31. Schmitz, A.; Stamminger, R. Usage behaviour and related energy consumption of European consumers for washing and drying. Energy Effic. 2014, 7, 937-954. [CrossRef]

32. Siebens, J. Extended Measures of Well-Being: Living Conditions in the United States: 2011; United States Census Bureau: Washington DC, USA, 2013; Volume 70, p. 136.

33. Allwood, J.M.; Laursen, S.E.; Rodríquez, C.M.; Bocken, N.M.P. Well Dressed? The Present and Future Sustainability of Clothing and Textiles in the United Kingdom; University of Cambridge: Cambridge, UK, 2006.

34. United States Environmental Protection Agency. Advancing Sustainable Materials Management: 2014 Fact Sheet; Office of Land and Emergency Management, United States Environmental Protection Agency: Washington, DC, USA, 2016.

35. Gracey, F.; Moon, D. Valuing our Clothes: The Evidence Base. Waste \& Resources Action Programme (WRAP). Available online: http:/ / www.wrap.org.uk/sites/files/wrap/10.7.12\%20VOC-\%20FINAL.pdf (accessed on 13 February 2017).

36. European Commission and the Council. Directive 2008/98/EC on Waste and Repealing Certain Directives. Official Journal of the European Union, 2008. Available online: http:/ /eur-lex.europa.eu/LexUriServ/ LexUriServ.do?uri=OJ:L:2008:312:0003:0030:EN:pdf (accessed on 30 March 2017).

37. Farrant, L.; Olsen, S.I.; Wangel, A. Environmental benefits from reusing clothes. Int. J. Life Cycle Assess. 2010, 15, 726-736. [CrossRef]

38. Morley, N.J.; Bartlett, C.; McGill, I. Maximising Reuse and Recycling of UK Clothing and Textiles: A Report to the Department for Environment, Food and Rural Affairs; Oakdene Hollins Ltd.: Aylesbury, UK, 2009.

39. Fisher, K.; James, K.; Maddox, P. Benefits of Reuse Case Study: Clothing; WRAP: Banbury, UK, 2011.

40. Koch, K.; Domina, T. Consumer textile recycling as a means of solid waste reduction. Fam. Consum. Sci. Res. J. 1999, 28, 3-17. [CrossRef]

41. Meade, A.W.; Craig, S.B. Identifying careless responses in survey data. In Proceedings of the 26th Annual Meeting of the Society for Industrial and Organizational Psychology, Chicago, IL, USA, 14-16 April 2011.

42. DeSimone, J.A.; Harms, P.D.; DeSimone, A.J. Best Practice Recommendations for Data Screening. J. Organ. Behav. 2015, 36, 171-181. [CrossRef]

43. Eurostat. Harmonized Index of Consumer Prices (HCIP). 2016. Available online: http://ec. europa.eu/eurostat/tgm/table.do?tab=table\&init=1\&plugin=1\&language=en\&pcode=teicp030 (accessed on 14 February 2017).

44. Hempel, A. Konsumethik und Premiumsegment. Konzept zur Kundenbindung und Neukundengewinnung im Premiumsegment des Deutschen Modemarktes unter Besonderer Berücksichtigung einer Konsumethik; Hamburger Schriften zur Marketingforschung; Hampp: Munich, Mering, 2010. (In German)

45. Kim, H.S.; Damhorst, M.L. Environmental concern and apparel consumption. Cloth. Text. Res. J. 1998, 16, 126-133. [CrossRef]

46. Dagevos, H. Consumers as four-faced creatures. Looking at food consumption from the perspective of contemporary consumers. Appetite 2005, 45, 32-39. [CrossRef] [PubMed] 
47. Wedel, M.; Kamakura, W. Market Segmentation: Conceptual and Methodological Foundations, 2nd ed.; Kluwer Academic Publishers: Boston, MA, USA, 2000.

48. Kotler, P.; Roberto, N.; Lee, N. Social Marketing: Improving the Quality of Life, 2nd ed.; Sage Publications: Thousand Oaks, CA, USA, 2002.

49. Levi Strauss \& Co. The Life Cycle of a Jeans. Understanding the Environmental Impact of a Pair of Levi's ${ }^{\circledR}$ 501 ${ }^{\circledR}$ Jeans. 2015. Available online: http://levistrauss.com/wp-content/uploads/2015/03/Full-LCAResults-Deck-FINAL.pdf (accessed on 13 February 2017).

50. Bhardwaj, V.; Fairhurst, A. Fast fashion: Response to changes in the fashion industry. Int. Rev. Retail Distrib. Consum. Res. 2010, 20, 165-173. [CrossRef]

51. Weller, I. Sustainable consumption and production patterns in the clothing sector: Is green the new black? In Sustainability in Fashion and Textiles. Values, Design, Production and Consumption; Gardetti, M.A., Torres, A.L., Eds.; Greenleaf Publishing: Sheffield, UK, 2013; pp. 184-194.

52. Hiller, A.J. Challenges in researching consumer ethics: A methodological experiment. Qual. Mark. Res. Int. J. 2010, 13, 236-252. [CrossRef]

(C) 2017 by the authors. Licensee MDPI, Basel, Switzerland. This article is an open access article distributed under the terms and conditions of the Creative Commons Attribution (CC BY) license (http:/ / creativecommons.org/licenses/by/4.0/). 